\title{
2009/84
}

Neighborhood effects on unemployment?

A test à la Altonji

Claire Dujardin and Florence Goffette-Nagot

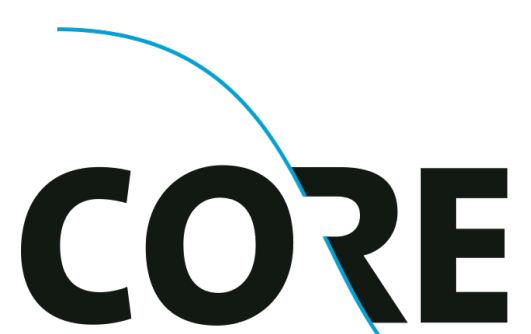

DISCUSSION PAPER

Center for Operations Research and Econometrics

Voie du Roman Pays, 34 B-1348 Louvain-la-Neuve Belgium http://www.uclouvain.be/core 


\title{
CORE DISCUSSION PAPER
}

$2009 / 84$

\section{Neighborhood effects on unemployment? A test à la Altonji}

\section{Claire DUJARDIN ${ }^{1}$ and Florence GOFFETTE-NAGOT ${ }^{2}$}

\author{
December 2009
}

\begin{abstract}
The aim of this paper is to test for the influence of neighborhood deprivation on individual unemployment probability in the case of Lyon (France). We estimate a bivariate probit model of unemployment and location in a deprived neighborhood. Our identification strategy is twofold. First, we instrument neighborhood type by the gender composition of household's children and the spouse's workplace. Second, we use the methodology proposed by Altonji et al. (2005), that in our case consists in making hypotheses as to the correlation between the unobservables that determine unemployment and the unobservables that influence the selection into neighborhood types. Our results show that the effect of neighborhood deprivation is not significantly different from zero in the bivariate probit with exclusion restrictions. We also show that a correlation of the unobservables as low as ten percent of the correlation of observables is sufficient to explain the positive neighborhood effect that is observed when endogeneity is not accounted for.
\end{abstract}

Keywords: neighborhood effects, unemployment, simultaneous probit models, instrumenta variables, selection on unobservables.

JEL Classification: R2, I32

${ }^{1}$ F.R.S.-FNRS and Université catholique de Louvain, CORE, B-1348 Louvain-la-Neuve, Belgium. E-mail: Claire.dujardin@uclouvain.be

${ }^{2}$ Université de Lyon, F-69003 Lyon, France; CNRS, GATE, UMR 5824, Ecully, F-69130, France.

E-mail: goffette-nagot@gate.cnrs.fr

Claire Dujardin thanks the F.R.S.-FNRS for financing a research stay at GATE. Florence Goffette-Nagot acknowledges funding from the MiRe (Ministère de l'Emploi, de la Cohésion sociale et du Logement and Ministère de la Santé et des Solidarités. Census data from the French National Institute for Statistics (Insee) was provided by the Centre Maurice Halbwachs. The authors gratefully thank the Division Logement (Insee) for the agreement Insee/Inra that allowed using data from the French Housing Survey.

This paper presents research results of the Belgian Program on Interuniversity Poles of Attraction initiated by the Belgian State, Prime Minister's Office, Science Policy Programming. The scientific responsibility is assumed by the authors. 


\section{Introduction}

A rapidly growing stream of research in the social interactions literature focuses on neighborhood effects, that is, the impact of neighbors' characteristics and behaviors on individual socioeconomic outcomes (Durlauf, 2004). In particular, theoretical and empirical evidence suggests that interactions with neighbors are likely to affect individual labor-market outcomes through peer effects and role models in the human capital acquisition process, attitudes toward work, and dissemination of information on job opportunities. Arnott and Rowse (1987) show that lessable learners exert negative externalities on the learning process of other students. Bénabou (1993) argues that the cost of education acquisition may be influenced by education decisions of neighbors. Wilson (1987) explains that the lack of successful role models among older adults in deprived neighborhoods may influence youths' motivations and attitudes toward work. The role of social networks on information about job openings has also been highlighted, especially for low-skilled workers who often resort to informal search modes such as personal contacts (see Selod and Zenou, 2006 and Zenou, 2008 for theoretical models). As a consequence, the percentage of employed individuals in the neighborhood may influence other residents' access to job opportunities (Topa, 2001; Bayer et al., 2005). Finally, the stigmatization of deprived neighborhoods may lead employers to discriminate workers on the basis of their residential location (territorial discrimination; see Zenou and Boccard, 2000).

Measuring neighborhood effects raises the issue of location choice endogeneity, which generates correlated effects (Moffitt, 2001; Durlauf, 2004). Indeed, urban economics has recognized for long that individuals with similar socio-economic characteristics, labor-market outcomes, and unobservable traits tend to sort themselves into certain areas of the urban space. Therefore, studies that do not control for the endogeneity of social group will yield biased results (Krauth, 2006). The inadequate correction for this bias has been put forward to explain the great divergence of results obtained by empirical studies (Ginther et al., 2000) and is one of the major focuses of recent research on neighborhood effects.

This paper aims to test for the existence of neighborhood effects on unemployment focusing on the endogeneity issue (i) by accounting for the sorting into neighborhoods based on observed and unobserved characteristics and (ii) by using two different and complementary identification strategies thus providing a robustness test of the results. The application is on French data. 
Indeed, theories highlighting the impact of neighborhood composition on individual labor-market outcomes have emerged in the context of U.S. metropolitan areas and empirical studies are numerous in this context. In contrast, empirical evidence on this matter in Europe is recent and still scarce. Exceptions include Fieldhouse (1999) and Bolster et al. (2007) on Britain, Dujardin et al. (2008) on Belgium, Andersson (2004) and Galster et al. (2008) on Sweden. ${ }^{1}$ In France, neighborhood effects have been studied (alongside with spatial mismatch effects) for Paris (Gobillon and Selod, 2007; Gobillon et al., 2009) and Bordeaux (Gaschet and Gaussier, 2004). However, these French studies do not perfectly deal with the endogeneity of neighborhood choice, which is the main focus of the present paper.

In the following, we estimate the impact of neighborhood deprivation on individual unemployment probabilities in Lyon, the 2nd largest French city. In order to take into account threshold effects, as suggested by Crane (1991), in the relationship between neighborhood deprivation and individual outcomes, we classify neighborhoods as deprived or not on the basis of a data analysis step. Then a simultaneous model of unemployment and neighborhood type is estimated. Two different identification strategies are used. In a first strategy, identification relies classically on exclusion restrictions. We use the gender composition of household's children as well as the spouse's workplace as instruments for neighborhood type. This set of instruments is carefully discussed and their relevance and validity are thoroughly tested. Second, following Altonji et al. (2005), we estimate this simultaneous probit model with no exclusions but imposing constraints on the correlation of error terms that amount to making hypotheses as to the intensity of selection into deprived neighborhoods based on unobservables. These assumptions allow to place bounds to the neighborhood effects on unemployment. To our knowledge, this application of the Altonji et al. method to the estimation of neighborhood effects is novel, one exception in a similar spirit being Krauth (2009).

Our results show that living in the $25 \%$ most deprived neighborhoods of Lyon significantly increases unemployment probabilities in a naive probit model that do not control for the endogeneity of location. However, the effect of neighborhood deprivation is not significant anymore once endogeneity is properly dealt with in a simultaneous probit specification with exclusion restrictions. Moreover, the second identification strategy, based on the correlation of error terms, suggests that only a small amount of correlation between the unobservables is

\footnotetext{
${ }^{1}$ We restrict here ourselves on studies of neighborhood effects on labor-market outcomes exclusively. Note however that other types of outcomes have been studied in the European context, including France.
} 
sufficient to explain the positive neighborhood effect that is observed when endogeneity is not accounted for.

The paper proceeds with Section 2 which defines the endogeneity issue and presents the various identification strategies used in the literature. Section 3 describes the database and gives a brief description of the spatial structure of Lyon. Section 4 presents our econometric model and identification strategies. Results are presented in Section 5. Section 6 concludes.

\section{Identification of neighborhood effects}

In a widely cited article, Manski (1993) identifies three types of mechanisms which explain the fact that individuals belonging to the same group tend to behave similarly: (i) endogenous effects wherein an individual's behavior is influenced by the average behavior in the group, (ii) contextual effects wherein an individual's behavior is influenced by the average characteristics in the group, and (iii) correlated effects, wherein similar behaviors in a group are the result of exposure to common unobserved factors or of non random group selection.

The goal of contemporaneous work on social interaction effects is to disentangle these different kinds of mechanisms. Indeed, social interaction effects, of which neighborhood effects are a special case defined on a geographical basis, consist in endogenous and contextual effects, each of which having different policy implications (Moffitt, 2001; Glaeser and Scheinkman, 2001). Correlated effects, if not corrected for, bias the estimates of endogenous and contextual effects (Dietz, 2002; Durlauf, 2004). Indeed, correlated effects arise because individuals (or households) are not distributed at random across social groups (or neighborhoods). On the contrary, individuals self-select into neighborhoods on the basis of their individual characteristics, which are also likely to influence the outcome or behavior of interest. Some of these characteristics are observed and can be controlled for in a simple regression analysis. But others are unobserved to the researcher (for example, motivations or abilities). This generates a nonzero correlation between the unobserved determinants of the outcome and unobserved determinants of neighborhood belonging, which is likely to yield biased neighborhood effect estimates. Recent studies have highlighted the reduction of estimated social interaction effects that stems from correcting for such biases (Ginther et al., 2000; Krauth, 2006). 
In this context, the objective of this article is to estimate neighborhood effects on unemployment, i.e. contextual effects and endogenous effects together, while purging the bias due to correlated effects. In doing so, we consider the correction for self-selection into neighborhoods as a precondition to the estimation of neighborhood effects and we leave the distinction between endogenous and contextual effects for future research.

Various strategies have been proposed in the empirical literature to correct for non random group selection in neighborhood effect studies. Quasi-experimental situations, in which households are moved from one neighborhood to another through an exogenous governmental intervention are considered as providing quite reliable estimates of neighborhood effects. The best-known examples of such interventions are the Gautreaux Program and the Moving To Opportunity Program (see Oreopoulos, 2003, for a review). While such studies have been able to show the existence of neighborhood effects on teenagers behaviors and outcomes, it seems that neighborhood effects on adult labor-market outcomes are of much lower importance, if any (Kling et al., 2007; Katz et al., 2001). Another strand of literature uses longitudinal data and estimates neighborhood effects through fixed-effect models, thus allowing to control for individual unobserved characteristics that are constant across time (Weinberg et al., 2004; Galster et al., 2008). For example, Weinberg et al. (2004) find that hours worked are influenced by neighborhood characteristics but comparison of results with and without fixed-effects suggests that naive estimates are strongly overestimated. A final approach consists in instrumental variables techniques, i.e. replacing the neighborhood characteristic by a set of variables that are correlated with the latter but not with the unobserved determinants of the outcome. Unfortunately, finding a good instrument is a difficult task. Most studies up to now have used instruments defined on an aggregate basis, in general city-level variables. For example, Foster and McLanahan (1996) use city-level labor-market conditions as instruments for neighborhood dropout rate in their study of educational outcomes. Evans et al. (1992) use a similar strategy. Cutler and Glaeser (1997) study the influence of city-level segregation level on education and income for blacks, using public finance and topographic characteristics as instruments. However, such instruments have been criticized as it is not clear how they can account for neighborhood effects within cities (Durlauf, 2004) and it is likely that aggregate-level instruments may actually increase biases (Rivkin, 2001). Instruments defined at the individual level have been used in other research contexts. For example, Currie and Yelowitz (2000) and Goux and Maurin (2005) estimate the effect of public housing occupancy and overcrowded housing respectively on educational outcome 
using as instrument the sex composition of children. Dujardin and Goffette-Nagot (2009) also use the sex composition of children to identify the effect of public housing occupancy on unemployment. In a slighly different setting, Goux and Maurin (2007) use information on neighbors' month of birth as an instrument to study the influence of neighbors on educational outcomes. We are not aware of any use of such type of instruments in the study of neighborhood effects on labor-market outcomes.

Besides these strategies to overcome self-selection issues, a stream of research has adopted a completely different perspective which consists in evaluating how large selection based on unobservables has to be to invalidate naive estimates (as suggested by Glaeser, 1996). Recent work by Altonji et al. (2002b, 2005, 2008) and by Krauth $(2006,2007)$ are examples of such studies. In particular, in the absence of a relevant instrument, Altonji et al. (2002b, 2005) use the amount of selection on observables as a guide to the amount of selection on unobservables to bound estimates of the effect of Catholic schools, a clearly endogenous variable with respect to educational attainment.

As explained in details in Section 4, the present paper builds on the last two identification strategies highlighted above. In a first step, we resort to instrumental variables and estimate a simultaneous model of unemployment and neighborhood type, using instruments defined at the individual level. In a second step, we use a strategy similar to the one proposed by Altonji et al. (2005).

\section{Data and basic evidence}

\subsection{Data}

The empirical analysis conducted in this paper is based on data extracted from the 1999 French Population Census. It corresponds to a 1:20th sample of individuals for whom detailed personal and household characteristics are provided (age, gender, education, employment status, occupational status, household type, etc) along with the characteristics of the other members of his/her household. In addition, census data are particularly useful in the context of neighborhood effects studies as it is (to our knowledge) the sole dataset in France to provide information on residential location at a fine spatial scale: the Iris zone. Iris zones are either municipalities if 
those have less than 10,000 inhabitants and subdivisions of around 2,000 inhabitants otherwise. They have been created in order to represent homogeneous entities in terms of housing and population. They are generally formed around well identified groups of buildings and respect frontiers such as main avenues, rivers or railways. They will be called neighborhoods in the rest of the paper, for the sake of simplicity. In addition to the 1:20th sample, census data also gathers summary statistics at the neighborhood level, including indicators of the socioeconomic composition of the population based on exhaustive information. These indicators will be used in the next subsection to define a typology of neighborhoods based on the deprivation level, i.e. the interest variable in our econometric model.

This paper focuses on Lyon, the second largest city in France. Its agglomeration (defined here by its urban unit) extends over a $958 \mathrm{~km}^{2}$ area and hosts around 1.3 million inhabitants. ${ }^{2}$ It counts 540 neighborhoods ${ }^{3}$ which have on average 2,428 inhabitants, a figure more or less comparable to the size of American Census tracts used in previous studies of neighborhood effects in the U.S. Lyon is characterized by the existence of pockets of poverty in the close periphery of its center (the so-called "banlieues") and thus appears to be an adequate case study to test for the existence of neighborhood effects. Figure 1 maps the percentage of unemployed workers among labor-force participants at the neighborhood level. In most American cities, central neighborhoods exhibit higher unemployment rates than peripheral neighborhoods. In Lyon, the neighborhoods with the lowest unemployment rates are also found in the far periphery, but Figure 1 shows that the highest unemployment rates are found in the close periphery of Lyon's municipality and not in the center. The unemployment spatial structure is also quite related to the distribution of educational levels, professional statuses and ethnic minorities. It is also strongly related to the location of public housings, which is very typical of French cities where public housing projects built in the 1970's play a key role in spatially concentrating low-income households. As a consequence, one can suspect the existence of neighborhood effects affecting labor-market outcomes of individuals located in these neighborhoods.

\footnotetext{
${ }^{2}$ The urban unit, unité urbaine in French, is a set of municipalities, the territory of which is covered by a built-up area of more than 2000 inhabitants, and in which buildings are separated by no more than 200 meters. The urban unit of Lyon consists of 102 municipalities. For practical reasons, we added three municipalities which are enclosed within the urban unit of Lyon (Quincieux, Saint-Germain-au-Mont-D'Or and Poleymieux-au-MontD'Or).

${ }^{3} \mathrm{~A}$ few Iris having less than 200 people had to be deleted for confidentiality reasons.
} 


\subsection{Definition of deprived neighborhoods}

Our empirical model estimates neighborhood effects on unemployment probabilities. We have thus to define a relevant measure of neighborhood characteristics. Literature on neighborhood effects shows that a wide variety of neighbors' characteristics is likely to affect individual unemployment propensity. Introducing all of them is not desirable because of the high degree of correlation observed between such variables, which may cause instability in the parameters and significance levels (O'Regan and Quigley, 1998). Furthermore, several authors (for example, Crane, 1991; Weinberg et al., 2004) suggest the existence of potential threshold effects, which make the relationship between the level of deprivation and the intensity of neighborhood effects non linear. Therefore, we don't introduce linearly a deprivation index in the unemployment equation but rather, and for the sake of simplicity, a dummy variable representing the classification of a neighborhood as deprived.

Consequently, we build a typology of neighborhoods aiming at reflecting for each neighborhood its social composition and the ensuing neighborhood effects that potentially affect labor-market outcomes. This classification is based on a set of variables chosen in order to account for the most-often cited mechanisms by which neighborhood might affect unemployment: distribution of population by educational levels, percentage of executives and blue-collars in the labor force, percentage of unemployment and long-term unemployment, percentage of household heads of foreign nationality, and percentage of lone-parent families. Each of these neighborhood characteristics is likely to affect individual unemployment propensity: high unemployment rates as well as high rates of foreigners influence the quality of social networks and decrease information on job opportunities; educational levels, income levels (proxied by professional statuses) and the percentage of lone-parent families are indicators of social and economic (un)success among neighbors, which generate contagion effects and a lack of role models; in addition, the percentage of foreign household heads and lone-parent families are often correlated to various social deviances, which give rise to stigmatization of neighborhoods. Note that we don't seek to disentangle these different mechanisms.

We treat this set of variables by means of standard factorial ecology methods (see for example Johnston et al., 2004) in order to build a composite indicator of neighborhood deprivation. We first run a Principal Component Analysis to define a number of non-correlated factors summarizing the information carried by these variables. As usual, only factors with eigenvalue 
above 1 are retained, that is in our case, two factors which together account for $90 \%$ of the variance of the initial set of variables (see Table A.1 in Appendix). The deprivation index is then defined as a linear combination of these two factors, each being weighted by the part of total variance it explains. The index ranges from -1.08 for the less deprived neighborhood to 2.64 for the most deprived. In order to deal with a dummy variable, we define cut-off values on this deprivation index in order to identify the most deprived neighborhoods of Lyon. We use alternatively cut-off values corresponding to the $35 \%, 25 \%$ and $15 \%$ most deprived neighborhoods, corresponding to deprivation index above $0.10,0.31$ and 0.73 respectively. The $25 \%$ classification will be our baseline neighborhood variable and will be used in most analyses, while the 35 and $15 \%$ will be used to test the sensitivity or our results to a move of the classification threshold.

As can be seen from Figure 2, deprived neighborhoods are spread in different parts of the city, still mostly concentrated in its eastern half. Table 1 shows the main characteristics of the $25 \%$ most deprived neighborhoods, as opposed to the rest of the agglomeration. These deprived neighborhoods are characterized by high unemployment rates (twice as high as the average unemployment rate in other neighborhoods), high percentage of foreigners (more than three times as high as in the rest of the agglomeration), low educational levels and professional statuses (for example, the percentage of individuals with a university degree is one third of the average corresponding percentage for other neighborhoods).

\subsection{Sample definition and first evidence}

Our joint model of unemployment probability and neighborhood type deals only with couple households, because the case of single adults suffers from a selection bias, young adults being less likely to form a separate household if they are unemployed. Moreover, the presence of a spouse gives us characteristics that will be used in the equation of neighborhood type. Finally, because dealing with women would imply to explain not only unemployment, but also labormarket participation, our study only concerns male household heads. We select, from the 1:20th census sample, individuals aged 19 to 64 and participating in the labor-market. Due to data availability on previous occupation, we delete individuals who never worked, that is only 18 individuals. The final sample contains 10,473 individuals, all of them being males. Our analysis therefore does not concern the population of women nor that of young males at the beginning 
of their career.

Table 2 displays the sample statistics by neighborhood type defined with the $25 \%$ threshold, for all exogenous variables that will be used in the empirical model. For each explanatory variable, the percentage of the sample in the category as well as the mean unemployment rate are provided. ${ }^{4}$ Deprived neighborhoods host one fifth of the individuals in our sample. Compared to individuals in other neighborhoods, those in deprived neighborhoods are less educated and have lower occupational statuses. ${ }^{5}$ Regarding demographic variables, they have the same age structure but the proportion of foreigners is higher in deprived neighborhoods than in the rest of the agglomeration. Unemployment rates vary markedly with respect to the socioeconomic profile (younger individuals, foreigners, less educated and lower occupational statuses have higher unemployment rates), but also with respect to the neighborhood type. On average, individuals residing in deprived neighborhoods are more often unemployed (11\%, against $5 \%$ in the rest of the agglomeration). Moreover, for each socioeconomic category, unemployment rates in deprived neighborhoods are higher than unemployment rates of the corresponding category in the other neighborhoods.

This differenciated unemployment rate depending on neighborhood type raises several interpretations. First, this could account for neighborhood effects that increase the difficulties encountered by individuals on the labor-market when they live in a deprived neighborhood, such as peer effects, lack of role models, poor social networks or territorial discrimination. Second, this could be the consequence of a self-selection effect. Indeed, as rents vary according to the type of neighborhood, the less successful individuals on the labor market and people with a low attachment to the labor market are more likely to sort themselves into deprived neighborhoods (Zenou, 2008). Our econometric analysis is intended to disentangle these two mechanisms.

\footnotetext{
${ }^{4}$ Note that these percentages are slightly different from those displayed in Table 1 . Indeed, our sample consists only of male heads of couple households aged 19-64, whereas Table 1 corresponds to the whole population.

${ }^{5}$ In the whole paper, the following education levels will be used: No diploma, At most lower secondary school, Vocational training, High school final diploma, University degree. They correspond to the following French categories: no reported diploma, CEP or Brevet, CAP or BEP, Baccalauréat, DEUG or above, respectively. As regards the occupational status, intermediate professions include teachers and related, social and healthcare workers, clergy, civil service middle managers, sales and administrative middle managers, technicians and supervisors.
} 


\section{Method}

Our empirical model is intended to test for the existence of an effect of neighborhood deprivation on unemployment. The classical theory of job search ends up in the estimation of unemployment duration models, whereas the dataset we use only contains information on the current employment status. We therefore estimate the probability of unemployment. This reduced form is assumed to represent how the individual's situation affects both the arrival rate of job offers and his reservation wage. As already explained, neighborhood deprivation is endogenous because unobserved individual characteristics that influence residential choice are likely to influence labor-market outcomes. To control for endogeneity, we estimate a simultaneous probit model of unemployment and neighborhood type. Our first identification strategy is, classically, to use exclusion restrictions. However, because instrument choice is always questionable, we consider a second identification strategy, based on totally different assumptions, that has been proposed by Altonji et al. (2005). In a nutshell, this identifying strategy consists in making assumptions as to the level of selection on unobservables.

\subsection{Empirical model and econometric method}

The aim of our econometric model is to estimate jointly the unemployment probability and the probability of living in a deprived neighborhood. We therefore have a bivariate probit formed of an individual-level equation for unemployment and a household-level equation for the residential situation. It writes:

$$
\left\{\begin{aligned}
y_{1} & =1\left(\alpha y_{2}+X^{\prime} \beta_{1}+u_{1}>0\right) \\
y_{2} & =1\left(X^{\prime} \beta_{2}+u_{2}>0\right) \\
{\left[\begin{array}{l}
u_{1} \\
u_{2}
\end{array}\right] } & \sim N\left(\left[\begin{array}{l}
0 \\
0
\end{array}\right],\left[\begin{array}{ll}
1 & \rho \\
\rho & 1
\end{array}\right]\right)
\end{aligned}\right.
$$

where $y_{1}$ and $y_{2}$ are the probability of unemployment and the probability to live in a deprived neighborhood respectively. $X$ is a vector of exogenous covariates influencing the two outcomes (leaving aside the identification issue for the time being). The latent variable determining unemployment is assumed to be influenced by the dummy $y_{2}$ and $\alpha$ is an estimate of the intensity of neighborhood effects on unemployment probability. As we assume that the sorting 
of households into neighborhood types may be affected by unobserved characteristics influencing also unemployment, the correlation term between the residuals of the two probits $\left(u_{1}\right.$ and $\left.u_{2}\right)$ is supposed to be non-zero and equal to $\rho$.

This simultaneous probit model includes an endogenous observed discrete variable on its right hand side (the neighborhood type in the unemployment equation). It amounts consequently to a mixed model. A coherency condition, which imposes a triangular form, has to be verified in mixed models (Maddala, 1983; Blundell and Smith, 1994). The observed variable of unemployment cannot therefore be introduced in the neighborhood type equation. However, unemployment is likely to affect the household's income and therefore the probability to live in a deprived neighborhood. To account for this influence, we introduce all the observable characteristics determining unemployment probability in the neighborhood equation. The presence of unobservables that determine unemployment and therefore influence neighborhood type is likely to result in a correlation between the error terms of the two equations. The simultaneous estimation ensures that this correlation is explicitly dealt with, as the correlation matrix of error terms is estimated. ${ }^{6}$

Unemployment is explained, in a classical manner, by individual characteristics relative to experience (that will be proxied by age and its square to allow for a non-linear effect), education and previous occupation, because unemployment rates vary with skill level and professional status. Due to potential discrimination by employers, individual's nationality is included. It is also supposed to influence, in conjunction with the spouse's nationality, the access to information on job opportunities through the network of relatives. Because the spouse's educational level might be suspected to influence the individual's participation on the labor market, it is also included in the unemployment equation.

In the neighborhood equation, the educational levels of the individual and his spouse, individual's occupational status in previous job and age are proxies for the household's income, which plays a central role in residential choice. Further, there is some evidence that individuals of foreign origin are discriminated against on the renting market and are therefore more likely to be accommodated in public housing and in low-income neighborhoods. Dummies for the

\footnotetext{
${ }^{6}$ The relevance of this triangular specification can moreover be supported by the estimation of a reverse specification, in which the neighborhood type is explained by unemployment and no effect of neighborhood on unemployment is assumed. The estimation of such a model shows that there is no effect of unemployment on neighborhood choice, once the effect of observed characteristics is controlled for (results available from the authors on request).
} 
individual's and his spouse's nationalities account for these effects.

In summary, $X$ in system 4.1 is a vector of exogenous variables including a constant, individual's age and its square (expressed as units of ten years), nationality, diploma and previous occupation as well as the spouse's nationality and diploma (each of them being a set of dummy variables).

The sample log-likelihood function is written as the sum of $N$ individual contributions:

$$
\ln L=\sum_{i=1}^{N} \ln \Phi_{2}\left[q_{i 1}\left(X_{i}^{\prime} \beta_{1}+\alpha y_{i 2}\right), q_{i 2}\left(X_{i}^{\prime} \beta_{2}\right), q_{i 1} q_{i 2} \rho\right]
$$

where $q_{i j}=2 y_{i j}-1$ is equal to 1 whenever $y_{i j}$ is 1 and to -1 whenever $y_{i j}$ is 0 , subscript $i$ denotes individual $i$ and $\Phi_{2}($.$) is the bivariate normal cumulative distribution function.$

Such a system can be estimated by a maximum likelihood method. Endogeneity tests amount to test the significance of the correlation coefficient of residuals (Greene, 1998). Note that standard errors have to be corrected for within-neighborhood dependencies to account for common influences within neighborhoods, using Huber ajusted standard errors (Wooldridge, 2003).

\subsection{Instrumental variable identification}

A simultaneous probit model is formally identified based on functional form (Wilde, 2000). However, it is known that relying on functional form for identification can be misleading and some restrictions are required to base identification on meaningful grounds. ${ }^{7}$ We therefore use exclusion restrictions aimed at providing identification of the neighborhood effect, under the form of a vector $Z$ of covariates introduced in the equation of $y_{2}$, which gives:

$$
\left\{\begin{aligned}
y_{1} & =1\left(\alpha y_{2}+X^{\prime} \beta_{1}+u_{1}>0\right) \\
y_{2} & =1\left(X^{\prime} \beta_{2}+Z^{\prime} \gamma+u_{2}>0\right) \\
{\left[\begin{array}{l}
u_{1} \\
u_{2}
\end{array}\right] } & \sim N\left(\left[\begin{array}{l}
0 \\
0
\end{array}\right],\left[\begin{array}{ll}
1 & \rho \\
\rho & 1
\end{array}\right]\right)
\end{aligned}\right.
$$

The goal when choosing an exclusion restriction is to find a variable that affects the

\footnotetext{
${ }^{7}$ See for instance the comparison between 2SLS and bivariate probit methods in Altonji (2002a).
} 
choice of residential location while not being correlated with the probability of unemployment conditionally on the other covariates. In French cities, one important determinant of residential location is accommodation in public housing, which is a strong factor of income segregation. Indeed, a large part of the public housing stock was built under the form of large projects in city outskirts and public housing renters are therefore concentrated in specific neighborhoods. Still, being in public housing cannot be considered, in our views, as exogenous to unemployment. In a previous paper, we have shown that the gender composition of children influences the probability for a household to be accommodated in the public housing sector (Dujardin and Goffette-Nagot, 2009). The rationale for this is that parents having children of different genders are less likely to have a third child and this effect is stronger for those having first a girl. This ensues in a lower probability to be housed in the public housing sector and then also in deprived neighborhoods. Indeed, Table 2 shows that the percentage, among families with at least two children, of households having first a girl and then a boy is lower in deprived neighborhoods. The gender composition of children is therefore likely to influence location in a deprived neighborhood and it is our first instrument. It is however available only for households having two children or more.

Given the size of the agglomeration, workplace location is also an important determinant of residential location choice. We build a variable that takes value 1 if the workplace of the spouse (the individual's workplace not being usable for evident reasons) is in the eastern outskirts, that is more specifically, in the group of municipalities delineated on Figure A.1 in Appendix, ${ }^{8}$ where a large part of the deprived neighborhoods is located. The variable takes value 0 when the spouse does not work or works in other parts of the city. We observe that the household is more likely, ceteris paribus, to be located in a deprived neighborhood when the spouse works in the eastern part of the city: the percentage of households in deprived neighborhoods with this characteristic is $23.0 \%$ against $14.1 \%$ in other neighborhoods (Table 2); the variable is highly significant in a probit model of neighborhood type (Table 3).

We now examine the properties of these two instruments, i.e. their relevance and validity. We perform this analysis on the basis of linear probability specifications of our model, using

\footnotetext{
${ }^{8}$ These communes (Vaulx-en-Velin, Vénissieux, Décines, Bron, Saint-Priest, Lyon $8^{\circ}$ arrondissement, Villeurbanne, Saint-Fons, Feyzin) have been chosen so as to represent the main employment centers in the eastern outskirts. A small municipality located between Décines-Charpieu and Saint-Priest has not been taken into account due to the small number of jobs it has. The 8th district of Lyon's municipality has been included because it concentrates a lot of jobs.
} 
a GMM estimation to deal with the heteroskedasticity of linear probability models (see Baum et al., 2003). In this context, the relevance of the instrument $Z$ means that $\operatorname{Cov}\left(y_{2}^{*}, Z \mid.\right) \neq 0$, and the validity means that $\operatorname{Cov}\left(Z, u_{1}\right)=0$ with $u_{1}$ the error term in the interest equation. The relevance of instruments will be evaluated using classical F-tests performed on the 1st stage estimation, while the validity will be assessed, in the specifications where we have two instruments, using overidentification tests based on Hansen J statistic, which is adapted to GMM estimations.

Among our two instruments, only the spouse's workplace can be used on the whole sample. The gender composition of household's children is a second instrument for the subsample of families with at least two children. It allows us to perform an overidentification test on this subsample and thus to assess the validity of the first instrument.

Beginning with the relevance of the spouse's workplace instrument, the F statistic of significance in the first stage is 28.6 for the whole sample (Table 3, column 2), when a rule of thumb gives a threshold of 10 for a set of instruments to be considered as strong (Staiger and Stock, 1997). As to the validity of this instrument, we have to show that the spouse's workplace is not correlated to the unobservables that affect the individual's probability of unemployment. We first note that the communes chosen for the definition of this dummy do not host particularly low-skilled or temporarily jobs. On the contrary, this area has firms working for instance in the pharmaceutical sector, in the computer industry and four specialized hospitals. Therefore, it is not very likely that working in these communes is associated with a low attachment to the labor market for the spouse or the individual. In our sample, the percentage of unemployed is even smaller for the individuals whose spouse works in this area $(5.6 \%$ against $6.6 \%$ for the rest of the population, Table 2), which can be explained by the fact that spouses of employed workers are more likely to be employed due to assortative mating. However, this effect is fully explained by the observed characteristics: a simple probit of individual's unemployment probability shows that when controlling for other covariates, the coefficient of the spouse's workplace is not significant at any conventional level. ${ }^{9}$

Considering the subsample of families with at least two children provides us with a second instrument and thus with a formal validity test of the two instruments. We first check that changing the sample does not change the relevance of the spouse's workplace as an instrument.

\footnotetext{
${ }^{9} \mathrm{P}$-value 0.23 , detailed results available from the authors on request.
} 
Table 3 (column 4) shows that, although a little less significant, the spouse's workplace is a strong enough instrument for the sample of families. Adding the dummy for families having first a girl and then a boy decreases the global F statistic (Table 3, column 5), due to the fact that the girl-boy dummy is significant at the $10 \%$ level only. However, with a F statistic of 12.25 , this set of instruments can be considered as strong enough. Considering now the validity, we can first say that the children gender dummy can safely be considered as exogenous, because it is not chosen by the parents and there is no reason for it to affect the father's unemployment probability. ${ }^{10}$ We then consider the Hansen J statistic testing the joint validity of the two instruments. The value of the statistic is 0.53 (p-value 0.47 ), which indicates that the null hypothesis that the two intruments are jointly valid can not be rejected. The limits of this kind of tests are known: they can provide missleading results, as the null of orthogonality may be unrejected when the two instruments are endogenous but the biases that they induce are of similar sign and magnitude. However, we claim that performing such a test with two instruments having very different logics and of which one is clearly exogenous (the children gender composition) gives more reliability to the test.

\subsection{Identification $\grave{a}$ la Altonji}

As recalled above, the bivariate probit with an endogenous covariate is classically identified by introducing exclusion restrictions. Other types of restrictions can serve as identification means. As shown in a serie of papers by Altonji et al. (2002a, 2002b, 2005, 2008), it is possible, instead of relying on potentially disputable instruments, to make assumptions concerning the correlation between the unobservables determining the outcome and the endogenous variable. Considering system 4.1, this amounts to place constraints on the parameter $\rho$ and allows to have a restriction ensuring the identification of the endogenous variable coefficient.

Altonji et al. (2005) present their framework as consisting in making hypotheses as to the selection into the treatment (the endogenous variable) based on unobservables and seeing how the estimated effect of the endogenous variable varies depending on these hypotheses. The basic idea is that the degree of selection on observables into the treatment may be used as a guide for the degree of selection produced by unobservables. The extreme hypothesis of an equal amount

\footnotetext{
${ }^{10}$ See Angrist and Evans (1998) and Goux and Maurin (2005) for the use of this characteristic as a valid instrument.
} 
of selection on observables and unobservables allows the identification of a point estimate.

We briefly present here the conditions under which an "equal selection" based on observables and unobservables can be reasonably assumed. The details and justification of these conditions are formalized in Altonji et al. (2002b). The idea of "equal selection" considers that the outcome is determined by a set of factors, a part of which only is observable. If this set is large, so that none of these elements dominates the distribution of the outcome and of the endogenous variable, and if the observables are randomly selected among this set, then, because the observables and unobservables are treated symetrically, the treatment has the same relationship to the explained part of the outcome than to its unexplained part. A third hypothesis is required for equal selection to hold: the regression of $y_{2}^{*}$ on $y_{1}^{*}-\alpha y_{2}$ (with $y_{1}^{*}$ and $y_{2}^{*}$ the latent variables determining the outcome and the endogenous binary variable respectively) has to be equal to the regression of the part of $y_{2}^{*}$ that is orthogonal to $X$ on the corresponding part of $y_{1}^{*}-\alpha y_{2}$ (see Altonji et al., 2002b, for proof).

Under this set of assumptions, a formal condition is obtained that translates in the bivariate probit case to:

$$
\rho=\frac{\operatorname{Cov}\left(X^{\prime} \beta_{2}, X^{\prime} \beta_{1}\right)}{\operatorname{Var}\left(X^{\prime} \beta_{1}\right)}
$$

In words, the condition of equal selection on observables and unobservables amounts to placing a restriction on the correlation coefficient of the errors of the bivariate probit, which allows to obtain a point estimate of the coefficient of the endogenous variable. Because the hypothesis concerning the selection on unobservables provides an identifying assumption, no exclusion restriction is required and the bivariate probit writes as system 4.1.

We can now discuss whether the conditions for equal selection on observables and unobservables hold in our case. Variables that determine whether a person is unemployed at a point in time are diverse. We can consider them to be numerous and pertaining to different domains. Those domains are the personal characteristics determining skills (educational background, experience, other traits such as personal motivation), the characteristics of the local labor market, the sector of activity and the type of position in previous job, the social network of the person and personal characteristics that might serve as a basis for discrimination. Our covariates cover those different domains: education and age relate to skills and experience, nationality may generate discrimination, occupational status gives a proxy for the type of employment, while 
the spouse's educational level and nationality are proxies for the quality of the social network. However, it seems likely that those variables are strong determinants of unemployment probability. Moreover, age, occupation and education of the individual and education of his spouse are very important in determining the household's income, and therefore neighborhood choice. The condition of equal selection on unobservables and observables seems therefore too strong in our case. However, Altonji et al. (2002b) argue that in practice, this assumption can be viewed as giving a lower bound of the treatment effect, while the biased probit estimate provides an upper bound. ${ }^{11}$

We will therefore follow Altonji et al. (2005) and give three types of results:

- Sensitivity analysis: The bivariate probit is estimated with the correlation coefficient being constrained to different values, which serve as identification assumptions. This allows to scan the estimated effect of the endogenous variable over different values of the correlation.

- Equal selection: We assume the equality of selection on observables and unobservables. The likelihood of the bivariate probit is maximized under this constraint and a point estimate of the neighborhood effect is obtained.

- Assessing the amount of selection on unobservables required to explain the probit estimate: Following Altonji et al. (2005), one can formalize how large selection on unobservables is relative to selection on observables by writing:

$$
\frac{E\left(u_{1} \mid y_{2}=1\right)-E\left(u_{1} \mid y_{2}=0\right)}{\operatorname{var}\left(u_{1}\right)}=\lambda \frac{E\left(X^{\prime} \beta_{1} \mid y_{2}=1\right)-E\left(X^{\prime} \beta_{1} \mid y_{2}=0\right)}{\operatorname{var}\left(X^{\prime} \beta_{1}\right)}
$$

This equation represents that the relationship between the treatment and the mean index of unobservables that determine the outcome is $\lambda$ times as strong as the relationship between the treatment and the mean index of observables, after adjustments for variances. The condition of equality of selection on observables and unobservables (condition 4.4) is equivalent to $\lambda=1$.

It is then possible to compute how large $\lambda$, that is the selection on unobservables relative to the selection on the index of observables, would have to be for the naive estimate obtained in the probit to be entirely explained by selection. Altonji et al. (2002b) show that under

\footnotetext{
${ }^{11}$ Krauth (2006) gives a formal demonstration of this idea in a slightly different case.
} 
this hypothesis:

$$
\lambda=\hat{\alpha}\left(\frac{\operatorname{var}\left(y_{2}\right)}{\left.\operatorname{var}\left(\tilde{y_{2}}\right)\right)} \frac{\left[E\left(X^{\prime} \beta_{1} \mid y_{2}=1\right)-E\left(X^{\prime} \beta_{1} \mid y_{2}=0\right)\right]}{\operatorname{var}\left(X^{\prime} \beta_{1}\right)}\right)^{-1}
$$

with $\tilde{y}_{2}$ the residual of a regression of $y_{2}$ on $X .^{12}$

\section{Results}

Two kinds of results are presented in this section: results of the simultaneaous probit model with exclusion restrictions in Section 5.1 and robustness checks based on the identification strategy proposed by Altonji et al. (2005) in Section 5.2.

\subsection{Simultaneous probit model estimates}

Table 4 presents marginal effects of the simultaneous probit of neighborhood deprivation (defined here as the $25 \%$ most deprived neighborhoods) and unemployment for the whole sample with the spouse's workplace as an instrument (columns 2-3) and for families with at least two children with two different instrumentations. The first one uses the spouse's workplace (columns 4-5), whereas the second has two instruments: the spouse's workplace and the gender composition of children (columns 6-7).

On the whole sample, the probability to live in a deprived neighborhood is influenced by the individual's and his spouse's nationality (column 3). Being of foreign nationality increases by about 10 points the probability to live in a deprived neighborhood. Being of French nationality born abroad increases this probability by 6 points. The effect of education level is quite strong as well. Having no diploma or at most a lower secondary education raises the likelihood to be in a deprived neighborhood. Note that the effect of the spouse's education is higher than that of the individual: the possibility to have a second wage in the household and the level of this wage particularly influences residential choice. Finally, the professional category also markedly

\footnotetext{
${ }^{12}$ More precisely, let's note $X^{\prime} \beta_{2}$ and $\tilde{y_{2}}$ the predicted value and residual of a regression of $y_{2}$ on $X$, so that $\tilde{y_{2}}$ is orthogonal to $X^{\prime} \beta_{2}$. Treating $\alpha$, the coefficient of the endogenous, as if it were estimated by a linear regression of the latent variable $y_{1}^{*}$ on $y_{2}$ and $X$ and supposing that the bias in the probit equation is the same as the one based on an OLS estimation, the estimated coefficient verifies: plim $\hat{\alpha}=\alpha+\frac{\operatorname{var}\left(y_{2}\right)}{\operatorname{var}\left(\tilde{y_{2}}\right)}\left[E\left(u_{1} \mid y_{2}=1\right)-E\left(u_{1} \mid y_{2}=0\right)\right]$. Replacing $E\left(u_{1} \mid y_{2}=1\right)-E\left(u_{1} \mid y_{2}=0\right)$ by its expression from 4.5 and supposing that there is no endogenous effect $(\alpha=0)$, it is possible to solve for $\lambda$ (reminding that $\operatorname{var}\left(u_{1}\right)=1$ ) which gives formula 4.6.
} 
impacts neighborhood choice, with the expected effect. We also observe the effect of the two instruments, that were already commented in Section 4.2. Families with at least two children behave in the same way, with an additional effect of age, younger families being more likely to live in deprived neighborhoods.

There are not much differences between the two samples as to the determinants of unemployment (columns 2 and 4). The probability of unemployment has a non-monotonic relationship with age, with a minimum at age 44 . Compared to the intermediate profession category, individuals who were formerly independant workers or executives are less likely to be unemployed. A slight effect of diploma is also observed, the low categories having higher probabilities of unemployment. This effect appears both through the individual's and his spouse's education, which can be attributed to the fact that the spouse's diploma is a proxy for the quality of the social network of the household and to assortative mating. There is a rather strong effect of the individual's nationality, which is more intense for individuals of foreign nationality than for individuals of French nationality born in France.

Finally, we observe that the coefficient of neighborhood type is unsignificant whatever the sample and for the two instrumentations in the case of families with two children and more. By comparison, a probit estimation of unemployment yields a marginal effect of living in a deprived neighborhood of 2.1 probability points on the whole sample (column 2 of Table 3) and 2.6 probability points on the sample of families with children (column 4 of Table 3), which is comparable in magnitude to the effect of being French born abroad. Of course, we know that this effect is a naive estimate of the real neighborhood effect, because the single probit estimation does not control for the endogeneity of neighborhood type. This naive effect completely disappears once the endogeneity of residential location is accounted for. Note that the estimated coefficient is even negative on the whole sample, which, as will be explained in the next section, is consistent with the high positive value of the residuals' correlation coefficient. However, neither the neighborhood coefficient, nor the correlation coefficient are significant in any of the three models.

In summary, the estimated results for the whole sample and for the subsample with children are consistent, showing an absence of effect of living in a deprived neighborhood on unemployment. It is important to recall that our instrumentation relies on two instruments having very different logics and that passed the instrument validity test run on the sample of 
families with at least two children. Moreover, the GMM estimation of the linear probability model allows to calculate the Stock-Wright statistic, which is a test of the two joint hypotheses that the instruments are valid and that the coefficient of the endogenous variable is null (Baum et al., 2003). For the three estimations, the Stock-Wright statistic shows that these hypotheses can not be rejected at any conventional level (Table 3). This result is useful in particular for the whole sample, for which it provides a formal test of exogeneity of the only instrument available in this case and an additional result in favor of the absence of effect of neighborhood deprivation on unemployment probability.

In order to establish more firmly our results, we provide in the following robustness checks that have two goals: (i) to use a completely different identification strategy that does not rely on the quality of instruments; (ii) to explore the robustness of our main result to a different neighborhood classification and to a focus on different subpopulations. Indeed, even if there is no effect of being in the $25 \%$ most deprived neighborhoods, would it be that concentrating the analysis on the most deprived neighborhood gives a different result? Moreover, because the intensity of neighborhood effects is likely to vary depending especially on education, we may find neighborhood effects on subsamples defined on the basis of educational levels. Note that the subsample of families with two children and more was useful to have a second instrument allowing to test for the validity of the spouse's workplace as an instrument. As the rest of our analysis does not rely on instrumental variables, the following results concern the whole sample.

\subsection{Analysis à la Altonji}

Table 5 presents in three different panels the results of the different identifying assumptions presented in section 4.3, which consists in (i) estimating the effect of living in a deprived neighborhood for different constraints on the value of the correlation coefficient $\rho$ (panel A), (ii) estimating the neighborhood effect assuming the equality of selection on observables and unobservables (panel B) and (iii) estimating what amount of selection on unobservables would be needed, relative to the selection on observables, to completely explain the effect of deprived neighborhood found in naive probits (panel C). This is done for three different neighborhood classifications (the baseline $25 \%$ classification as well as the $35 \%$ and $15 \%$ classifications) and for three educational samples: the whole sample (10,473 individuals), the low-educated (education up to A-level; 5,737 individuals) and the higher-educated (university level diploma; 
4,736 individuals). This gives nine combinations of neighborhood classification and educational subsamples, which correspond to the different columns of Table 5.

\subsubsection{Sensitivity to correlation in unobservables}

Estimated coefficients of the neighborhood variable corresponding to a correlation coefficient varying between 0.00 and 0.25 are presented in panel A of Table 5. Assuming that unobservables determining the two outcomes are not correlated (i.e. $\rho=0$ ) corresponds to the probit estimate and yields in the nine cases positive effects for deprived neighborhood, as already observed in Table 3. As expected, assuming a higher correlation of unobservables decreases the estimated effect of neighborhood in all the cases we consider. For the whole sample and whatever the neighborhood classification, the effect of neighborhood type vanishes when the correlation is increased from 0.05 to 0.1 . We even observe that imposing a correlation above 0.15 yields negative marginal effects. This observation is consistent with the sorting of individuals into neighborhood types. Indeed, imposing a high positive correlation of the error terms assumes that the individuals that have unobserved characteristics that favor the location in deprived neighborhoods also have unobservables that increase their unemployment probability. For this to be consistent with a moderate probit marginal effect, it has to be that the neighborhood type itself has a favorable effect on unemployment. In other words, the higher the sorting based on unobservables, the lower is the real effect of neighborhood for a given probit estimate, up to a negative effect.

It is also worth noting that the estimated neighborhood effect varies monotonically with the correlation coefficient. This result shows that it will be possible, as suggested by Altonji et al. (2002b), to build a confidence interval for the neighborhood effect based on assumptions as to the domain covered by the correlation of unobservables.

Focusing more particularly on the differences between the two educational subsamples, we first note that the neighborhood type coefficient varies with respect to the subsamples and with the neighborhood classification within each subsample. However, their standard deviations do not permit to make any conclusion as to the differences between these estimates, as confidence intervals of the point estimates overlap. Furthermore, we expect that working on subsamples defined based on education decreases the share of explanatory power of the model that is due 
to observable characteristics and therefore gives more weight to unobservables. As a result, the positive effect of neighborhood type estimated on these two subsamples is expected, when imposing some correlation on unobservables, to disappear more quickly than for the whole sample. This is indeed what is observed in our results. In particular, the effect of living in the $15 \%$ more deprived neighborhoods for the low educated is divided by almost three with a 0.05 correlation compared to the probit estimate. This means that the 2.1 marginal effect given by the probit model in this case (Table 5 , column 6 ) is very possibly entirely due to the effect of selection on unobservables. This is true for the two educational subsamples, whatever the neighborhood classification retained. The only exception concerns the highly educated in the $15 \%$ most deprived neighborhoods, for whom a higher correlation is required for the 4.0 marginal effect to be explained by selection based on unobservables. But the effect still vanishes at a low level of correlation, actually between 0.05 and 0.1 .

In summary, this sensitivity analysis shows that a small correlation of unobservables affecting the two outcomes of interest would be sufficient to produce the neighborhood effect that is estimated based on probit models. This result is robust with respect to subsamples defined based on education and to the particular threshold used for the neighborhood classification. However, the actual magnitude of the correlation of unobservables is of course unknown. This is why, following Altonji et al. (2005), we continue the analysis by using the amount of selection on observables as a benchmark for the amount of selection on unobservables.

\subsubsection{Assuming equal selection on unobservables and observables}

We consider here the assumption of equal selection into neighborhood types based on observables and unobservables. Panel $\mathrm{B}$ of Table 5 gives the neighborhood marginal effect for the bivariate probit (equation 4.1) estimated under the constraint $\rho=\operatorname{Cov}\left(X^{\prime} \beta_{2}, X^{\prime} \beta_{1}\right) / \operatorname{Var}\left(X^{\prime} \beta_{1}\right)$ and the resulting correlation coefficient. The estimated correlation coefficients are high, reflecting the high level of correlation in the explained part of the two outcomes, neighborhood type and unemployment. This ensues from the high level of urban segregation along age, education, nationality and occupational status, which are all important determinants of unemployment as well. Imposing such a high level of correlation of unobservables yields, in conformity with the results of the sensitivity analysis, negative coefficients for the neighborhood type in the unemployment equation. Such a negative effect of neighborhood deprivation is of course unlikely 
to be real and reflects rather that such a high level of correlation is unlikely to hold in the data.

As developed in Section 4, the assumption of equal selection is in our case an extreme hypothesis. Indeed, as our observed variables include age, education and nationality, we can think that very important determinants of neighborhood choice are already taken into account. As a result, we think that the real amount of selection on unobservables is likely to be lower than the selection on observables, but still strictly positive. Given this and given that the previous subsection showed that the effect of neighborhood decreases monotonically with the correlation of unobservables, one can consider the neighborhood effect estimated under the assumption of equal selection as a lower bound of the real neighborhood effect and the estimate obtained with the probit model, which considers that there is no selection based on unobservables, as the upper bound. All the hypotheses between these two benchmarks can be considered. It is then important to note that in the nine cases considered in Table 5, the lower value for the effect of neighborhood is negative, which means that the zero value, which is the result of the IV identification method, is in the confidence interval for the value of the neighborhood effect constructed based on the two extreme hypotheses of equal selection and no selection. Furthermore, a strictly positive effect of neighborhood type holds only if the level of selection on unobservables is low. In the following, a more informal analysis is carried, that assesses the amount of selection on unobservables required to explain the probit effect.

\subsubsection{Amount of correlation of unobservables required for the probit neighborhood effect to be entirely due to the endogeneity bias}

We finally turn to the last robustness check, which consists in evaluating how strong the selection on unobservables needs to be, relative to the selection on observables, so as to discard any effect of neighborhood type. The results of this step are in the last panel of Table 5 .

The two previous series of results showed, for instance for the whole sample and the $15 \%$ classification, that a 0.10 correlation of unobservables $(\rho)$ is enough to cancel out the probit marginal effect and that the correlation in the indexes of observables $\left(\operatorname{Cov}\left(X^{\prime} \beta_{2}, X^{\prime} \beta_{1}\right) / \operatorname{Var}\left(X^{\prime} \beta_{1}\right)\right)$ is 0.81 . Results for the other classifications and for the two subsamples are similar. Accordingly, it is expected that a level of selection on unobservables small in front of the selection on observables is enough to cancel out the effect of neighborhood type. 
Consistent with this observation, we find that a very low level of selection on unobservables relatively to the selection on observables is enough to explain the positive probit estimate of neighborhood type in all the cases. For the whole sample and whatever the neighborhood classification, a selection on unobservables as low as $6 \%$ of the selection on observables is enough to produce the estimated probit effect. Only in the case of the low educated sample and the $35 \%$ neighborhood classification is the quantity of required selection on unobservables slightly above $10 \%$ of the selection on observables. This remains however low, and allows us to conclude that this result is a strong argument against the existence of any effect of neighborhood type on unemployment probability in our data.

\subsection{Results synthesis}

Our results show that being in a deprived neighborhood could increase the probability of unemployment by 2.1 points if one were to take the probit estimate at face value. However, this estimate clearly suffers from an endogeneity bias and can only be considered as a higher bound of the real neighborhood effect. The lower bound of the estimated effect is obtained when considering that the correlation of unobservables influencing neighborhood type and unemployment is as high as the correlation of observable determinants. This is of course an extreme assumption, that leads to an implausible negative effect of neighborhood deprivation on unemployment probability. In any case, the real neighborhood effect is on this interval, which contains the null value.

For example, for the whole sample and the $15 \%$ neighborhood classification again, the naive probit marginal effect is 2.5 probability points. The sensitivity analysis shows that this effect decreases rapidly when the correlation is fixed to higher values. Assuming as much selection on unobservables as on observables, that is 0.82 , leads to an implausible negative effect of -16.3 probability points. The real neighborhood effect lies on this interval. It is very likely that even if not as high as the correlation on observables, some selection on unobservables happens, and the sensitivity analysis shows that a correlation of unobservables slightly above 0.05 produces a null marginal effect of neighborhood type. This set of results is sufficient to conclude that being located in the $15 \%$ most deprived neighborhoods in Lyon has no effect on unemployment probability. The results in the other cases are of similar magnitude. 
Finally, the informal computation suggested by Altonji et al. (2005) reported in section 5.2.3 shows that the correlation of unobservables being only 5 to $10 \%$ of the correlation of observables is enough to explain the positive effect estimated in probit models. Such a low level of correlation is very likely to happen in such a context, although these results per se are not enough to formally reject a positive effect of neighborhood deprivation on unemployment.

Consistently, the results of the simultaneous probit model, of which identification relies on a valid instrumentation, also points to a null effect of neighborhood deprivation on unemployment probability. All these results give converging elements based on different points of view. As a result, we are allowed to conclude that we were not able to demonstrate the existence of any neighborhood effect on unemployment in Lyon.

\section{Conclusion}

The objective of this paper was to examine how unemployment probabilities are influenced by location in a deprived neighborhood in a French city (Lyon). However, estimating properly the effect of neighborhood composition on unemployment is a difficult task, because labor-market outcomes and residential choices are intrinsically related. Therefore, it raises the issue of location choice endogeneity which, if not corrected for, is likely to bias the estimates of neighborhood effects. No perfect solution to this problem exists at present.

In this context, the main contribution of our work is to use two different identification strategies, which provide converging results. First, we estimate a simultaneous model of two probit equations, one for unemployment probability, and the second for location in a deprived neighborhood, allowing for non zero correlation between the error terms of both equations. Identification is achieved classically through exclusion restrictions on the basis of two instruments: the gender composition of household's children and an indicator variable for the spouse working in the eastern outskirts of the agglomeration. Results show that the naive detrimental effect found in simple probits completely disappears with the simultaneous probit estimates, whatever the instrument used and for both the whole sample and the sample of families with at least two children. Second, we estimate the same simultaneous model, without exclusion restrictions but imposing different constraints on the correlation between error terms, which permit point identification of neighborhood effects. This second strategy amounts to making hypotheses as 
to the degree of selection into deprived neighborhoods based on unobservables. Using different hypotheses as to this selection leads to the same result as the IV method: under reasonable assumptions as to this selection, it is not possible to demonstrate the existence of any significant effect of neighborhood deprivation on unemployment probability. Sensitivity analyses based on different subsamples defined on the basis of educational level and different neighborhood classifications also yield converging results.

In conclusion, our results do not provide any support to the hypothesis according to which living in a deprived neighborhood increases unemployment probabilities, once the endogeneity of residential choices is dealt with. It therefore highlights the importance of properly taking endogeneity into account in neighborhood effects studies. Besides, our results converge with those obtained in quasi-experimental designs which do not show any significant effect of residential moves on labor-market outcomes (Kling et al., 2007). Our result is also consistent with findings by Bolster et al. (2007), who show the absence of neighborhood effect on income dynamics, using panel data.

This result suggests that neighborhood effects found in naive models, as simple probit estimates, are in fact entirely due to the sorting into deprived neighborhoods of individuals with unobserved characteristics that are detrimental in finding a job. However, this result does not mean that public policies targeting specific neighborhoods, instead of specific individuals, are unneeded. Indeed, as highlighted by Bolster et al. (2007), given the high level of spatial sorting of households by socioeconomic category and also with a smaller intensity by unobserved characteristics, targeting specific areas is probably an easy way of targeting specific groups of individuals. Moreover, whereas it seems from our results that neighborhood deprivation has no effect on unemployment, it could well have an effect on other outcomes, such as adolescent educational outcomes or health.

Finally, we would like to stress the methodological contribution of our work. Indeed, neighborhood effects studies based on cross-section data are hampered by the difficulty of finding valid instruments. We hope that our analysis will show that it is possible, by exploiting the complementarity between the IV method and the à la Altonji approach, to provide robust results in this research area. This is a new track of research, that should reveal particularly fruitful in a domain where the identification issue is so crucial, and in contexts where quasi-experimental situations are scarce. 


\section{References}

Altonji, J.G., Elder, T.E., Taber, C.R. (2002a) An Evaluation of Instrumental Variable Strategies for Estimating the Effects of Catholic Schools. NBER Working Paper, no. 9358.

Altonji, J.G., Elder, T.E., Taber, C.R. (2002b) Selection on Observed and Unobserved Variables: Assessing the Effectiveness of Catholic Schools. Manuscript, Dept. Economics, Northwestern University.

Altonji, J.G., Elder, T.E., Taber, C.R. (2005) Selection on Observed and Unobserved Variables: Assessing the Effectiveness of Catholic Schools. Journal of Political Economy, 113: 151-184.

Altonji, J.G.n Elder, T.E., Taber, C.R. (2008) Using selection on observed variables to assess bias from unobservables with evaluating Swan-Ganz Catheterization. American Economic Review: Papers \& Proceedings, 98(2): 345-350.

Andersson, E. (2004) From valley of sadness to hill of happiness: the significance of surroundings for socioeconomic career. Urban Studies, 41(3): 641-659.

Angrist, J., Evans, W. (1998) Children and their parent's labor supply: evidence from exogenous variation in family size. American Economic Review, 88: 450-477.

Arnott, R., Rowse, J. (1987) Peer group effects and the educational attainment. Journal of Public Economics, 32(3): 287-305.

Baum C.F., Schaffer, M.E., Stillman S. (2003) Instrumental variables and GMM: Estimation and testing. Stata Journal, 3: 1-31.

Bayer P., Ross, S., Topa, G., (2005) Place of work and place of residence: informal hiring networks and labor market outcomes. NBER Working Papers, , no. 11019.

Bénabou, R. (1993) Workings of a city: location, education and production. Quarterly Journal of Economics, 108(3): 619-652.

Blundell, R., Smith, R.J. (1994) Coherency and estimation in simultaneous models with censored or qualitative dependent variables. Journal of Econometrics, 64: 355-373.

Bolster, A., Burgess, S., Johnston, R., Jones, K., Propper, C., Sarker, R. (2007) Neighbourhoods, 
households and income dynamics: a semi-parametric investigation of neighbourhood effects. Journal of Economic Geography, 7: 1-38.

Currie, J., Yelowitz, A. (2000) Are public housing projects good for kids? Journal of Public Economics, 75: 99-124.

Culter, D.M., Glaeser, E.L. (1997) Are ghettos good or bad? Quarterly Journal of Economics, 112(3): 827-872.

Dietz, R.D. (2002) The estimation of neighborhood effects in the social sciences: an interdisciplinary approach. Social Science Research, 31(4): 539-575.

Dujardin, C., Goffette-Nagot, F. (2009) Does public housing occupancy increase unemployment? Journal of Economic Geography, forthcoming.

Dujardin, C., Selod, H., Thomas, I. (2008) Residential segregation and unemployment: the case of Brussels. Urban Studies, 45(1): 89-113.

Durlauf, S.N. (2004) Neighborhood effects, in Henderson, J.V. and Thisse, J.-F. (ed.) Handbook of Regional and Urban Economics, vol. 4, Elsevier, 2173-2242.

Evans, W.N., Oates, W.E., Schwab, R.M. (1992) Measuring peer group effects: A study of teenage behavior. Journal of Political Economy, 100(5): 966-991.

Fieldhouse, E.A. (1999) Ethnic minority unemployment and spatial mismatch: the case of London. Urban Studies, 36(9): 1569-1596.

Foster, E.M., McLanahan, S. (1996) An illustration of the use of instrumental variables: do neighborhood conditions affect a young person's chance of finishing high school? Psychological Methods, 1(3):249-260.

Galster, G., Andersson, R., Musterd, S., Kauppinen, T.M. (2008) Does neighborhood income mix affect earnings of adults? New evidence from Sweden. Journal of Urban Economics, 63: 858-870.

Gaschet, F., Gaussier, N. (2004) Urban segregation and labour markets within the Bordeaux metropolitan area: an investigation of the spatial friction. Cahiers $d u$ GRES, ${ }^{\circ} 19$ (available at http://cahiersdugres.u-bordeaux4.fr/WP/index.php). 
Ginther, D., Haveman, R. and Wolfe, B. (2000) Neighborhood attributes as determinants of children's outcomes: how robust are the relationships? Journal of Human Resources, 35(4): 603-642.

Glaeser, E.L. (1996) Spatial effects upon employment outcomes: the case of New Jersey teenagers. Discussion. New England Economic Review, 58-64.

Glaeser, E.L., Scheinkman, J.A. (2001) Measuring social interactions. In: Durlauf, S.N. and Young, H.P. (ed.) Social dynamics, Mit Press., 83-132.

Gobillon, L., Selod, H. (2007) Ségrégation résidentielle, accès à l'emploi, et chômage : le cas de l'Ile-de-France. Economie et Prévision, 180-181: 19-38.

Gobillon, L., Magnac, T. and Selod, H. (2009) The effect of location on finding a job in the Paris region. Journal of Applied Econometrics, forthcoming.

Goux, D., Maurin, E. (2005) The effect of overcrowded housing on children's performance at school. Journal of Public Economics, 89: 797-819.

Goux, D., Maurin, E. (2007) Close neighbours matter: neighbourhood effects on early performance at school. The Economic Journal, 117:1193-1215.

Greene, W.H. (1998) Gender Economics Courses in Liberal Arts Colleges: Further Results. Journal of Economic Education, 29: 291-300.

Johnston, R.J., Jones, K., Burgess, S., Propper, C., Sarker, R. and Bolster, A. (2004) Scale, factor analyses, and neighborhood effects. Geographical Analysis, 36(4): 350-368.

Katz, L.F., Kling, J.R., Liebman, J.B. (2001) Moving to Opportunity in Boston: early results of a randomized mobility experiment. Quarterly Journal of Economics, 116(2): 607-654.

Kling, J.R., Liebman, J.B., Katz, L.F. (2007) Experimental analysis of neighborhood effects. Econometrica, 75(1): 83-119.

Krauth, B. (2006) Simultation-based estimation of peer effects. Journal of Econometrics, 113: 243-271.

Krauth, B. (2007) Peer and selection effects on youth smoking in California. Journal of Business and Economic Statistics, 25(3): 288-298. 
Krauth, B. (2009) Bounding a linear causal effect using relative correlation restrictions. Manuscript,

Dept. Economics, Simon Fraser University.

Maddala, G.S. (1983) Limited-dependent and Qualitative Variables in Econometrics. Cambridge:

Cambridge University Press.

Manski, C. (1993) Identification of endogenous social effects: the reflection problem. Review of Economic Studies, 60: 531-542.

Manski, C. (1995) Identification Problems in the Social Sciences. Cambridge, Harvard University Press.

Moffitt, R.A. (2001) Policy intercention, low-level equilibria, and social interactions. In: Durlauf, S.N. and Young, H.P. (ed.) Social dynamics, Mit Press, 45-82.

O'Regan, K.M., Quigley, J.M. (1998) Where youth live: economic effects of urban space on employment prospects. Urban Studies, 35(7): 1187-1205.

Oreopoulos, P. (2003) The long-run consequences of living in a poor neighborhood. Quarterly Journal of Economics, 118(4): 1533-1575.

Rivkin, S. (2001) Tiebout sorting, aggregation and the estimation of peer group effects. Economic of Education Review, 20: 201-209.

Selod, H., Zenou, Y. (2006) City structure, job search, and labor discrimination: theory and policy implications. Economic Journal, 116: 1057-1087.

Staiger, D., Stock, J.H. (1997) Instrumental Variables Regression with Weak Instruments. Econometrica, 65: 557-586.

Topa, G. (2001) Social interactions, local spillovers and unemployment. Review of Economic Studies, 68: 261-295.

Weinberg, B.A., Reagan, P.B., Yankow, J.J. (2004) Do neighborhoods affect hours worked? Evidence from longitudinal data. Journal of Labor Economics, 22(4): 891-924.

Wilde, J. (2000) Identification of multiple equation probit models with endogenous dummy regressors, Economic letters, 69: 309-312. 
Wilson, W.J. (1987) The Truly Disadvantaged. Chicago, University of Chicago Press.

Wooldridge, J. (2003) Cluster-sample methods in applied econometrics. American Economic Review, 93: 133-138.

Zenou, Y., Boccard, N. (2000) Labor discrimination and redlining in cities. Journal of Urban Economics, 48(2): 260-285.

Zenou, Y. (2008) Social interactions and labor market outcomes in cities. IFN Working Paper, no. 755 . 


\section{Appendix}

\begin{tabular}{lcc}
\hline & Factor 1 & Factor 2 \\
\hline Eigenvalue & 4.19 & 4.61 \\
Percent of variance explained & $41.86 \%$ & $46.15 \%$ \\
Loadings & & \\
\% families with foreign household head & $\mathbf{0 . 8 1 6}$ & -0.399 \\
\% monoparental households & $\mathbf{0 . 7 9 3}$ & -0.120 \\
\% pop. with at most lower secondary education & 0.510 & $\mathbf{- 0 . 8 2 4}$ \\
\% pop. with high school final diploma & -0.291 & $\mathbf{0 . 9 4 9}$ \\
\% pop. with a university degree & -0.212 & $\mathbf{0 . 9 6 8}$ \\
\% executives & -0.244 & $\mathbf{0 . 9 3 1}$ \\
\% blue-collars & 0.486 & $\mathbf{- 0 . 8 2 0}$ \\
\% unemployed workers & $\mathbf{0 . 9 2 1}$ & -0.308 \\
\% unemployed workers since more than one year & $\mathbf{0 . 9 0 8}$ & -0.314 \\
\% unemployed workers aged under 25 & $\mathbf{0 . 7 3 0}$ & -0.437 \\
\hline Only factors with eigenvalues superior or equal to 1 were retained.
\end{tabular}

Table A.1: List of variables used in the principal component analysis and their contributions to factors 


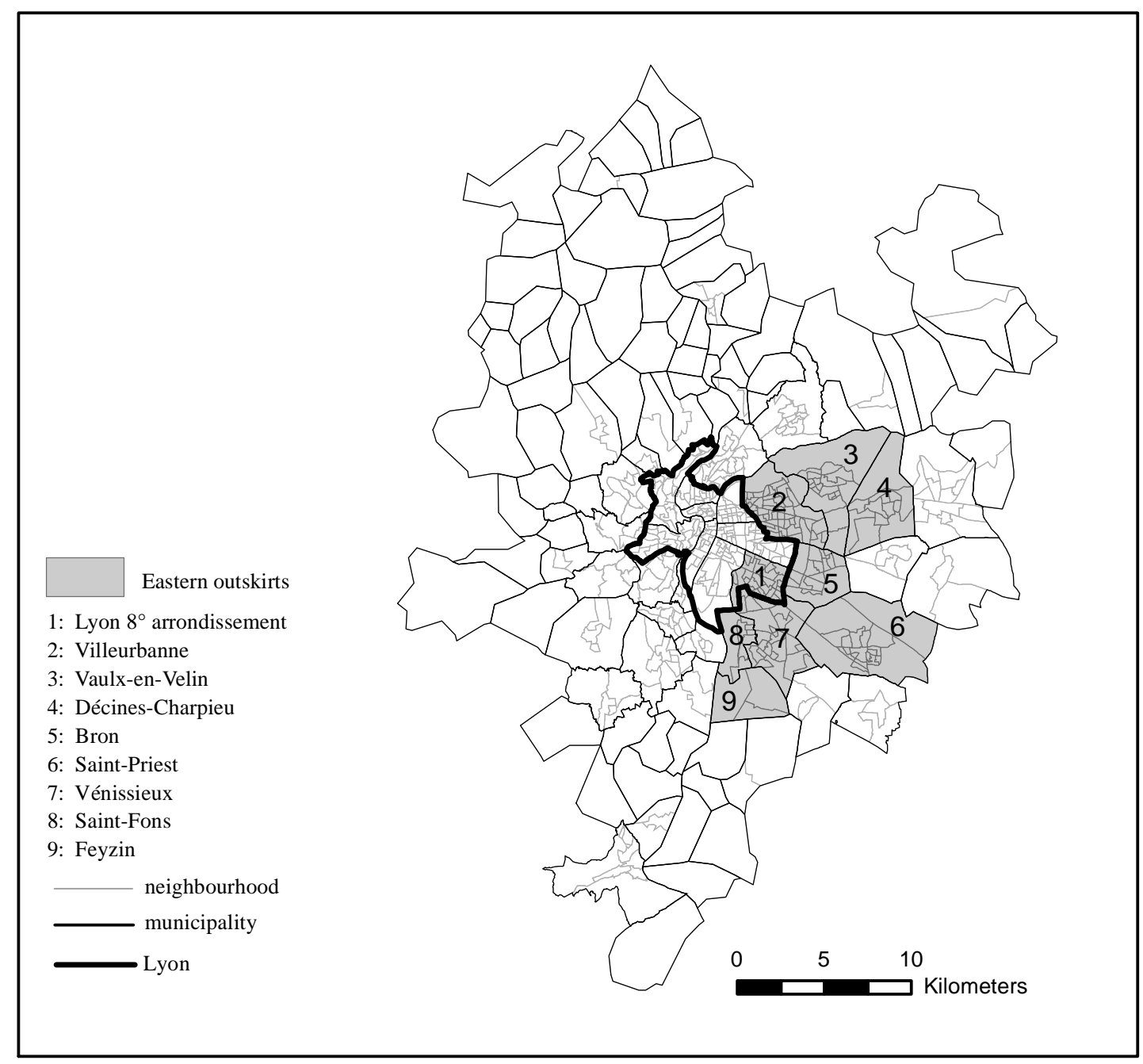

Figure A.1: Location of Eastern outskirts for the spouse's workplace variable 


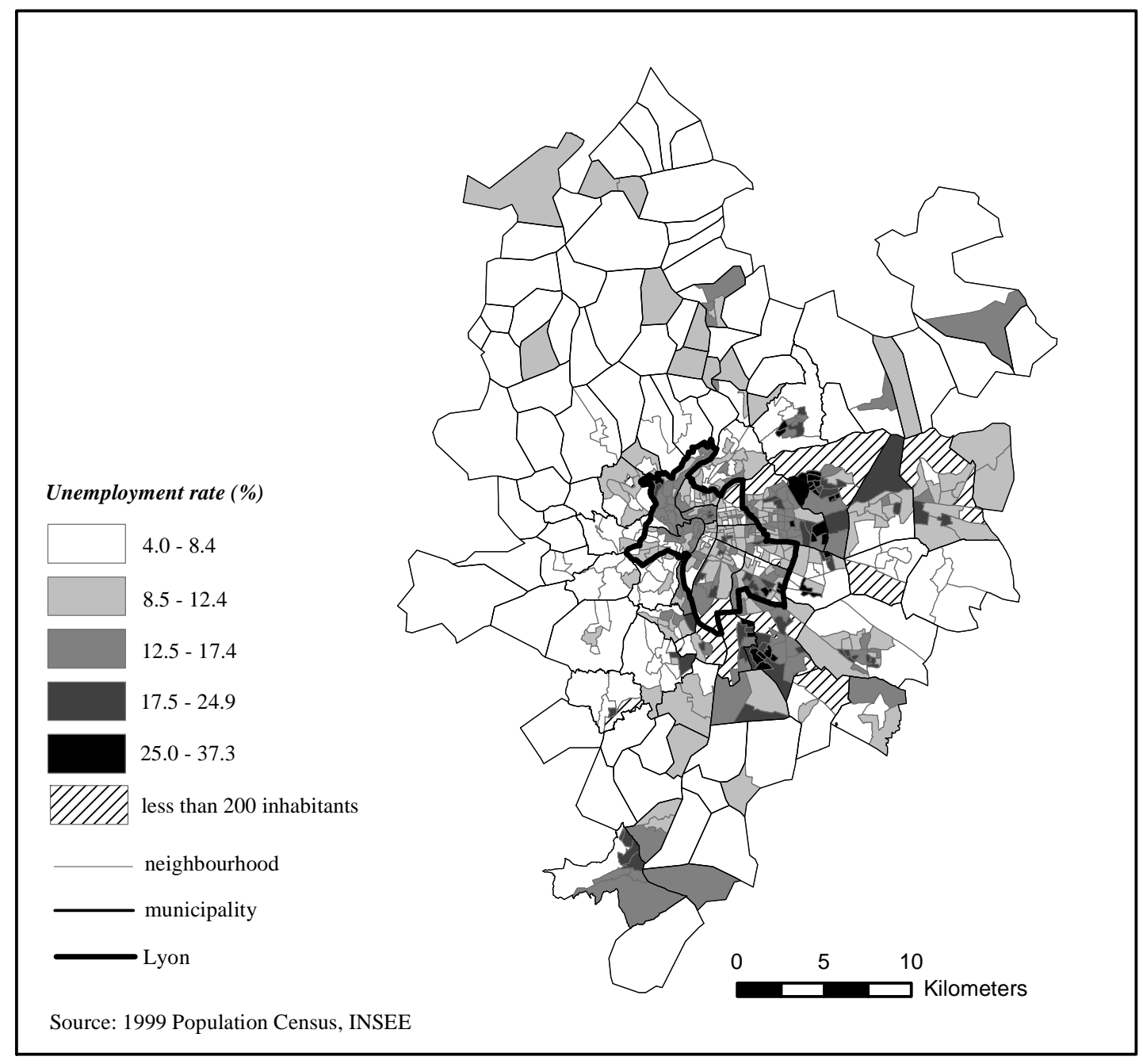

Figure 1: Percentage of unemployed workers within labor-force participants 
Deprivation index (percentiles)
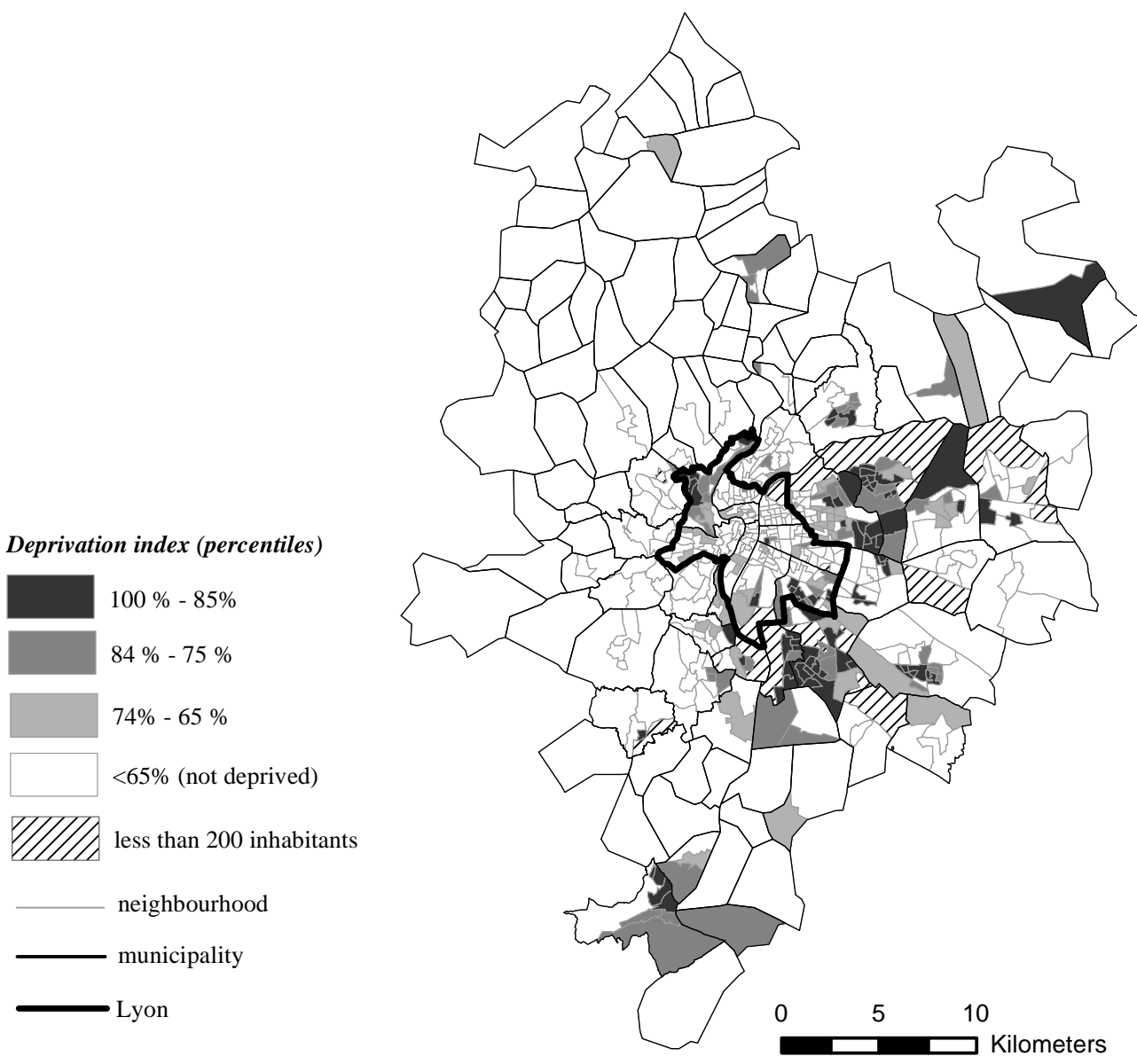

Source: Authors' calculations based on 1999 Population Census data, INSEE

Figure 2: Neighborhood typology 


\begin{tabular}{|c|c|c|c|c|c|c|c|}
\hline & \multicolumn{3}{|c|}{ Deprived neighborhoods } & \multicolumn{3}{|c|}{ Other neighborhoods } & \multirow{2}{*}{$\begin{array}{l}\text { Total } \\
\text { Mean }\end{array}$} \\
\hline & Mean & Min & Max & Mean & Min & Max & \\
\hline Public housing units (\%) & 51.9 & 0.0 & 98.5 & 11.1 & 0.0 & 70.9 & 21.3 \\
\hline \multicolumn{8}{|l|}{ Demography } \\
\hline Foreign household heads (\%) & 23.1 & 0.0 & 56.9 & 6.9 & 0.0 & 20.8 & 10.9 \\
\hline Lone-parent families (\%) & 18.9 & 7.1 & 33.3 & 11.8 & 0.0 & 28.6 & 13.5 \\
\hline \multicolumn{8}{|l|}{ Education levels } \\
\hline At most secondary edu. (\%) & 54.8 & 35.9 & 69.7 & 35.1 & 19.2 & 51.2 & 40.1 \\
\hline University degree (\%) & 10.6 & 4.0 & 34.9 & 29.3 & 7.2 & 54.3 & 24.6 \\
\hline \multicolumn{8}{|l|}{ Unemployment } \\
\hline Unemployed workers (\%) & 20.3 & 9.8 & 37.3 & 9.6 & 4.0 & 20.4 & 12.3 \\
\hline Unemp. for more than 1 year $(\%)$ & 11.1 & 4.6 & 22.0 & 4.7 & 1.3 & 11.2 & 6.3 \\
\hline \multicolumn{8}{|l|}{ Occupational status } \\
\hline Blue-collars (\%) & 38.0 & 14.2 & 62.9 & 16.2 & 2.8 & 46.0 & 21.7 \\
\hline Executives (\%) & 5.5 & 0.0 & 24.5 & 21.0 & 2.8 & 47.6 & 17.1 \\
\hline Population & 2369 & 270 & 5041 & 2443 & 247 & 5730 & 2425 \\
\hline Total population & \multicolumn{3}{|c|}{322,254} & \multicolumn{3}{|c|}{994,540} & $1,316,794$ \\
\hline Number of neighborhoods & \multicolumn{3}{|c|}{136} & \multicolumn{3}{|c|}{407} & 543 \\
\hline
\end{tabular}

Table 1: Mean characteristics of neighborhood by type (25\% most deprived neighborhoods versus others) 


\begin{tabular}{|c|c|c|c|c|c|c|}
\hline & \multicolumn{2}{|c|}{$\begin{array}{l}25 \% \text { most deprived } \\
\text { neighborhoods }\end{array}$} & \multicolumn{2}{|c|}{$\begin{array}{c}\text { Other } \\
\text { neighborhoods }\end{array}$} & \multicolumn{2}{|c|}{ Total } \\
\hline & $\begin{array}{c}\% \text { of } \\
\text { category }\end{array}$ & $\begin{array}{c}\% \text { in } \\
\text { unempl. }\end{array}$ & $\begin{array}{c}\% \text { of } \\
\text { category }\end{array}$ & $\begin{array}{c}\% \text { in } \\
\text { unempl. }\end{array}$ & $\begin{array}{c}\% \text { of } \\
\text { category }\end{array}$ & $\begin{array}{c}\% \text { in } \\
\text { unempl. }\end{array}$ \\
\hline Number of observations & 2215 & 11.1 & 8258 & 5.2 & 10,473 & 6.4 \\
\hline \multicolumn{7}{|l|}{$\begin{array}{l}\text { Personal characteristics } \\
\text { Age }\end{array}$} \\
\hline$=<30$ & 15.6 & 11.8 & 14.4 & 5.8 & 14.6 & 7.2 \\
\hline$>30$ and $=<45$ & 47.2 & 11.9 & 47.1 & 4.8 & 47.2 & 6.3 \\
\hline$>45$ & 37.2 & 9.7 & 38.5 & 5.4 & 38.2 & 6.3 \\
\hline \multicolumn{7}{|l|}{ Nationality } \\
\hline French born in France & 64.6 & 7.8 & 84.7 & 4.4 & 80.5 & 5.0 \\
\hline French born abroad & 13.8 & 11.1 & 9.0 & 7.0 & 10.0 & 8.2 \\
\hline Foreign nationality & 21.6 & 20.7 & 6.3 & 12.6 & 9.5 & 16.5 \\
\hline \multicolumn{7}{|l|}{ Education } \\
\hline No diploma & 26.3 & 16.5 & 10.2 & 8.4 & 13.6 & 11.7 \\
\hline At most lower sec. edu. & 16.6 & 11.4 & 11.7 & 7.2 & 12.7 & 8.4 \\
\hline Vocational training & 33.9 & 8.5 & 27.0 & 5.3 & 28.4 & 6.1 \\
\hline High school final diploma & 9.9 & 9.1 & 13.5 & 4.6 & 12.7 & 5.3 \\
\hline University diploma & 13.2 & 7.9 & 37.7 & 3.8 & 32.5 & 4.1 \\
\hline \multicolumn{7}{|l|}{ Occupational status } \\
\hline Farmer or independent worker & 6.6 & 7.5 & 11.3 & 2.8 & 10.3 & 3.4 \\
\hline Executive & 7.8 & 6.9 & 28.9 & 3.2 & 24.4 & 3.5 \\
\hline Intermediate professions & 18.7 & 7.5 & 27.5 & 5.4 & 25.6 & 5.7 \\
\hline Office worker & 12.4 & 9.8 & 9.0 & 4.9 & 9.7 & 6.3 \\
\hline Blue-collar & 54.5 & 13.6 & 23.3 & 8.6 & 29.9 & 10.5 \\
\hline \multicolumn{7}{|l|}{ Characteristics of the spouse } \\
\hline \multicolumn{7}{|l|}{ Education } \\
\hline No diploma & 26.4 & 14.4 & 9.0 & 10.1 & 12.7 & 11.9 \\
\hline At most lower sec. edu. & 19.1 & 12.7 & 14.7 & 5.8 & 15.7 & 7.6 \\
\hline Vocational training & 27.2 & 9.6 & 20.9 & 4.9 & 22.2 & 6.1 \\
\hline High school final diploma & 11.5 & 8.6 & 17.6 & 4.0 & 16.3 & 4.7 \\
\hline University diploma & 15.7 & 7.8 & 37.8 & 4.5 & 33.1 & 4.8 \\
\hline \multicolumn{7}{|l|}{ Nationality } \\
\hline French born in France & 67.0 & 8.6 & 86.0 & 4.5 & 82.0 & 5.3 \\
\hline French born abroad & 12.1 & 13.0 & 8.2 & 6.3 & 9.1 & 8.2 \\
\hline Foreign nationality & 20.1 & 17.7 & 5.8 & 13.0 & 8.9 & 15.3 \\
\hline \multicolumn{7}{|l|}{ Household characteristics } \\
\hline Girl-Boy (a) & 23.0 & 12.5 & 25.2 & 4.3 & 24.7 & 6.1 \\
\hline Spouse works in eastern outskirts & 23.5 & 7.1 & 15.1 & 4.9 & 16.8 & 5.6 \\
\hline
\end{tabular}

(a) For households having at least 2 children

Table 2: Summary statistics of the estimation sample 


\begin{tabular}{|c|c|c|c|c|c|}
\hline & \multicolumn{2}{|c|}{ All individuals } & \multicolumn{3}{|c|}{$>=2$ children } \\
\hline & Unemp. & Neighb. & Unemp. & Neighb. & Neighb. \\
\hline Deprived neighborhood (25\%) & $\begin{array}{c}0.0213^{* * *} \\
(0.0063)\end{array}$ & & $\begin{array}{c}0.0265^{* * *} \\
(0.0082)\end{array}$ & & \\
\hline \multicolumn{6}{|l|}{ Personal characteristics } \\
\hline Age (x 10 yrs) & $\begin{array}{c}-0.0808^{* * *} \\
(0.0179)\end{array}$ & $\begin{array}{l}-0.0448 \\
(0.0372)\end{array}$ & $\begin{array}{c}-0.0840^{* *} \\
(0.0369)\end{array}$ & $\begin{array}{c}-0.3066^{* * *} \\
(0.0735)\end{array}$ & $\begin{array}{c}-0.3038^{* * *} \\
(0.0734)\end{array}$ \\
\hline Squared-age (x 10 yrs) & $\begin{array}{c}0.0092^{* * *} \\
(0.0022)\end{array}$ & $\begin{array}{c}0.0032 \\
(0.0043)\end{array}$ & $\begin{array}{l}0.0092 * * \\
(0.0044)\end{array}$ & $\begin{array}{c}0.0325 * * * \\
(0.0084)\end{array}$ & $\begin{array}{c}0.0321^{* * *} \\
(0.0084)\end{array}$ \\
\hline \multicolumn{6}{|l|}{ Nationality } \\
\hline French born in France & Ref. & Ref. & Ref. & Ref. & Ref. \\
\hline Foreign nationality & $\begin{array}{c}0.0560^{* * *} \\
(0.0133)\end{array}$ & $\begin{array}{c}0.0942^{* * *} \\
(0.0204)\end{array}$ & $\begin{array}{c}0.0711^{* * *} \\
(0.0201)\end{array}$ & $\begin{array}{c}0.0895^{* * *} \\
(0.0293)\end{array}$ & $\begin{array}{c}0.0900 * * * \\
(0.0294)\end{array}$ \\
\hline French born abroad & $\begin{array}{c}0.0200^{* *} \\
(0.0088)\end{array}$ & $\begin{array}{c}0.0600 * * * \\
(0.0147)\end{array}$ & $\begin{array}{c}0.0368 * * * \\
(0.0126)\end{array}$ & $\begin{array}{c}0.0714^{* * *} \\
(0.0207)\end{array}$ & $\begin{array}{c}0.0715^{* * *} \\
(0.0207)\end{array}$ \\
\hline \multicolumn{6}{|l|}{ Education } \\
\hline No diploma & $\begin{array}{c}0.0176 \\
(0.0118)\end{array}$ & $\begin{array}{c}0.0582^{* * *} \\
(0.0178)\end{array}$ & $\begin{array}{c}0.0161 \\
(0.0145)\end{array}$ & $\begin{array}{c}0.0414^{*} \\
(0.0251)\end{array}$ & $\begin{array}{c}0.0413 \\
(0.0251)\end{array}$ \\
\hline At most lower sec. edu. & $\begin{array}{l}0.0186^{*} \\
(0.0111)\end{array}$ & $\begin{array}{c}0.0435^{* *} \\
(0.0181)\end{array}$ & $\begin{array}{c}0.0131 \\
(0.0143)\end{array}$ & $\begin{array}{c}0.0280 \\
(0.0267)\end{array}$ & $\begin{array}{c}0.0277 \\
(0.0267)\end{array}$ \\
\hline Vocational training & $\begin{array}{c}0.0018 \\
(0.0086)\end{array}$ & $\begin{array}{c}0.0229 \\
(0.0150)\end{array}$ & $\begin{array}{c}0.0002 \\
(0.0111)\end{array}$ & $\begin{array}{c}0.0185 \\
(0.0233)\end{array}$ & $\begin{array}{c}0.0180 \\
(0.0233)\end{array}$ \\
\hline High school final diploma & Ref. & Ref. & Ref. & Ref. & Ref. \\
\hline University diploma & $\begin{array}{l}-0.0017 \\
(0.0093)\end{array}$ & $\begin{array}{c}-0.0273^{*} \\
(0.0148)\end{array}$ & $\begin{array}{c}0.0148 \\
(0.0144)\end{array}$ & $\begin{array}{l}-0.0134 \\
(0.0251)\end{array}$ & $\begin{array}{l}-0.0143 \\
(0.0250)\end{array}$ \\
\hline \multicolumn{6}{|l|}{ Occupational status } \\
\hline Farmer or independent worker & $\begin{array}{c}-0.0291^{* * *} \\
(0.0063)\end{array}$ & $\begin{array}{c}-0.0473^{* * *} \\
(0.0140)\end{array}$ & $\begin{array}{c}-0.0191^{* *} \\
(0.0094)\end{array}$ & $\begin{array}{c}-0.0456^{* *} \\
(0.0222)\end{array}$ & $\begin{array}{c}-0.0454^{* *} \\
(0.0223)\end{array}$ \\
\hline Executive & $\begin{array}{c}-0.0188^{* * *} \\
(0.0067)\end{array}$ & $\begin{array}{c}-0.0677^{* * *} \\
(0.0115)\end{array}$ & $\begin{array}{l}-0.0146 \\
(0.0094)\end{array}$ & $\begin{array}{c}-0.0698 * * * \\
(0.0200)\end{array}$ & $\begin{array}{c}-0.0696^{* * *} \\
(0.0200)\end{array}$ \\
\hline Intermediate professions & Ref. & Ref. & Ref. & Ref. & Ref. \\
\hline Office worker & $\begin{array}{l}-0.0079 \\
(0.0079)\end{array}$ & $\begin{array}{c}0.0652^{* * *} \\
(0.0176)\end{array}$ & $\begin{array}{l}-0.0026 \\
(0.0116)\end{array}$ & $\begin{array}{c}0.1214^{* * *} \\
(0.0277)\end{array}$ & $\begin{array}{c}0.1228^{* * *} \\
(0.0278)\end{array}$ \\
\hline Blue-collar & $\begin{array}{c}0.0099 \\
(0.0072)\end{array}$ & $\begin{array}{c}0.1046^{* * *} \\
(0.0146)\end{array}$ & $\begin{array}{c}0.0100 \\
(0.0097)\end{array}$ & $\begin{array}{c}0.1313^{* * *} \\
(0.0222)\end{array}$ & $\begin{array}{c}0.1325^{* * *} \\
(0.0222)\end{array}$ \\
\hline \multicolumn{6}{|l|}{$\begin{array}{l}\text { Characteristics of the spouse } \\
\text { Education }\end{array}$} \\
\hline No diploma & $\begin{array}{l}0.0197^{*} \\
(0.0104)\end{array}$ & $\begin{array}{c}0.1353^{* * *} \\
(0.0200)\end{array}$ & $\begin{array}{c}0.0129 \\
(0.0136)\end{array}$ & $\begin{array}{c}0.1551^{* * *} \\
(0.0282)\end{array}$ & $\begin{array}{c}0.1538^{* * *} \\
(0.0282)\end{array}$ \\
\hline At most lower sec. edu. & $\begin{array}{l}0.0160^{*} \\
(0.0092)\end{array}$ & $\begin{array}{c}0.0761^{* * *} \\
(0.0160)\end{array}$ & $\begin{array}{c}0.0111 \\
(0.0127)\end{array}$ & $\begin{array}{c}0.0880^{* * *} \\
(0.0266)\end{array}$ & $\begin{array}{c}0.0866^{* * *} \\
(0.0266)\end{array}$ \\
\hline Vocational training & $\begin{array}{c}0.0067 \\
(0.0078)\end{array}$ & $\begin{array}{c}0.0768 * * * \\
(0.0145)\end{array}$ & $\begin{array}{c}0.0055 \\
(0.0105)\end{array}$ & $\begin{array}{c}0.0902^{* * *} \\
(0.0238)\end{array}$ & $\begin{array}{c}0.0889^{* * *} \\
(0.0238)\end{array}$ \\
\hline High school final diploma & Ref. & Ref. & Ref. & Ref. & Ref. \\
\hline University diploma & $\begin{array}{c}0.0118 \\
(0.0080)\end{array}$ & $\begin{array}{l}-0.0141 \\
(0.0129)\end{array}$ & $\begin{array}{c}0.0009 \\
(0.0109)\end{array}$ & $\begin{array}{l}-0.0244 \\
(0.0217)\end{array}$ & $\begin{array}{l}-0.0247 \\
(0.0217)\end{array}$ \\
\hline \multicolumn{6}{|l|}{ Nationality } \\
\hline French born in France & Ref. & Ref. & Ref. & Ref. & Ref. \\
\hline Foreign nationality & $\begin{array}{c}0.0166 \\
(0.0114)\end{array}$ & $\begin{array}{c}0.1188^{* * *} \\
(0.0232)\end{array}$ & $\begin{array}{c}0.0172 \\
(0.0149)\end{array}$ & $\begin{array}{c}0.1426^{* * *} \\
(0.0298)\end{array}$ & $\begin{array}{c}0.1407^{* * *} \\
(0.0296)\end{array}$ \\
\hline French born abroad & $\begin{array}{l}0.0161^{*} \\
(0.0089)\end{array}$ & $\begin{array}{c}0.0675^{* * *} \\
(0.0181)\end{array}$ & $\begin{array}{c}0.0100 \\
(0.0102)\end{array}$ & $\begin{array}{c}0.0777^{* * *} \\
(0.0238)\end{array}$ & $\begin{array}{c}0.0773^{* * *} \\
(0.0237)\end{array}$ \\
\hline \multicolumn{6}{|l|}{ Instruments } \\
\hline Spouse works in eastern outskirts & & $\begin{array}{c}0.1117^{* * *} \\
(0.0213)\end{array}$ & & $\begin{array}{c}0.1329 * * * \\
(0.0279)\end{array}$ & $\begin{array}{c}0.1338 * * * \\
(0.0280)\end{array}$ \\
\hline Girl-Boy & & & & & $\begin{array}{c}-0.0222^{*} \\
(0.0134)\end{array}$ \\
\hline \multicolumn{6}{|c|}{ Test on instruments from GMM estimation of linear probability models } \\
\hline First stage F-test [p-value] & & $28.57[0.000]$ & & $23.32[0.000]$ & $12.25[0.000]$ \\
\hline Stock-Wright [p-value] & & $1.90[0.168]$ & & $0.00[0.948]$ & $0.53[0.769]$ \\
\hline Overid. test Hansen J [p-value] & & - & & - & $0.530[0.466]$ \\
\hline Log-likelihood & -2349 & -4604 & -978.4 & -2143 & -2141 \\
\hline Pseudo- $\mathrm{R}^{2}$ & 0.0597 & 0.148 & 0.0999 & 0.192 & 0.192 \\
\hline Number of observations & & 473 & & 4849 & \\
\hline $\begin{array}{l}\text { Notes: }{ }^{* * *},{ }^{* *} \text { and }{ }^{*} \text { denote signific } \\
\text { Figures in parentheses give standarc } \\
\text { All models use } 25 \% \text { most deprived } n\end{array}$ & $\begin{array}{l}\text { ce at the } 19 \\
\text { rrors, corre } \\
\text { hborhoods } \\
\text { er). }\end{array}$ & $\begin{array}{l}5 \% \text { and } 10 \% \\
\text { ed for within } \\
\text { neighborhor }\end{array}$ & $\begin{array}{l}\text { cespective } \\
\text { oorhood } \mathrm{c} \\
\text { able and }\end{array}$ & $\begin{array}{l}\text { dencies. } \\
\mathrm{r} \text { all indivi }\end{array}$ & in the \\
\hline
\end{tabular}

Table 3: Marginal effects from simple probits of unemployment and location in deprived neighborhoods 


\begin{tabular}{|c|c|c|c|c|c|c|}
\hline \multirow{3}{*}{ Exclusions } & \multirow{2}{*}{\multicolumn{2}{|c|}{$\begin{array}{c}\text { All individuals } \\
\text { Spouse's workplace }\end{array}$}} & \multicolumn{4}{|c|}{$>=2$ children } \\
\hline & & & \multicolumn{2}{|c|}{ Spouse's workplace } & \multicolumn{2}{|c|}{$\begin{array}{c}\text { Spouse's workplace } \\
\text { \& Girl-Boy }\end{array}$} \\
\hline & Unemp. & Neighb. & Unemp. & Neighb. & Unemp. & Neighb. \\
\hline Deprived neighborhood (25\%) & $\begin{array}{l}-0.0329 \\
(0.0304)\end{array}$ & & $\begin{array}{c}0.0106 \\
(0.0304)\end{array}$ & & $\begin{array}{c}0.0026 \\
(0.0306)\end{array}$ & \\
\hline \multicolumn{7}{|l|}{ Personal characteristics } \\
\hline Age (x 10 yrs) & $\begin{array}{c}-0.0852^{* * *} \\
(0.0196)\end{array}$ & $\begin{array}{l}-0.0465 \\
(0.0372)\end{array}$ & $\begin{array}{c}-0.0888^{* *} \\
(0.0391)\end{array}$ & $\begin{array}{c}-0.3080^{* * *} \\
(0.0735)\end{array}$ & $\begin{array}{c}-0.0918^{* *} \\
(0.0398)\end{array}$ & $\begin{array}{c}-0.3055^{* * *} \\
(0.0733)\end{array}$ \\
\hline Squared-age (x 10 yrs) & $\begin{array}{c}0.0096^{* * *} \\
(0.0023)\end{array}$ & $\begin{array}{c}0.0035 \\
(0.0043)\end{array}$ & $\begin{array}{c}0.0097 * * \\
(0.0046)\end{array}$ & $\begin{array}{c}0.0327^{* * *} \\
(0.0084)\end{array}$ & $\begin{array}{c}0.0100^{* *} \\
(0.0046)\end{array}$ & $\begin{array}{c}0.0324^{* * *} \\
(0.0084)\end{array}$ \\
\hline \multicolumn{7}{|l|}{ Nationality } \\
\hline French born in France & Ref. & Ref. & Ref. & Ref. & Ref. & Ref. \\
\hline Foreign nationality & $\begin{array}{c}0.0672^{* * *} \\
(0.0171)\end{array}$ & $\begin{array}{c}0.0931^{* * *} \\
(0.0203)\end{array}$ & $\begin{array}{c}0.0734^{* * *} \\
(0.0213)\end{array}$ & $\begin{array}{c}0.0892^{* * *} \\
(0.0293)\end{array}$ & $\begin{array}{c}0.0748^{* * *} \\
(0.0216)\end{array}$ & $\begin{array}{c}0.0895^{* * *} \\
(0.0293)\end{array}$ \\
\hline French born abroad & $\begin{array}{c}0.0257^{* *} \\
(0.0107)\end{array}$ & $\begin{array}{c}0.0590^{* * *} \\
(0.0147)\end{array}$ & $\begin{array}{c}0.0384^{* * *} \\
(0.0134)\end{array}$ & $\begin{array}{c}0.0709 * * * \\
(0.0208)\end{array}$ & $\begin{array}{c}0.0394^{* * *} \\
(0.0137)\end{array}$ & $\begin{array}{c}0.0707^{* * *} \\
(0.0208)\end{array}$ \\
\hline \multicolumn{7}{|l|}{ Education } \\
\hline No diploma & $\begin{array}{l}0.0231^{*} \\
(0.0131)\end{array}$ & $\begin{array}{c}0.0577 * * * \\
(0.0179)\end{array}$ & $\begin{array}{c}0.0169 \\
(0.0144)\end{array}$ & $\begin{array}{c}0.0412 \\
(0.0251)\end{array}$ & $\begin{array}{c}0.0174 \\
(0.0146)\end{array}$ & $\begin{array}{c}0.0411 \\
(0.0252)\end{array}$ \\
\hline At most lower sec. edu. & $\begin{array}{l}0.0224^{*} \\
(0.0119)\end{array}$ & $\begin{array}{c}0.0434^{* *} \\
(0.0182)\end{array}$ & $\begin{array}{c}0.0135 \\
(0.0143)\end{array}$ & $\begin{array}{c}0.0278 \\
(0.0267)\end{array}$ & $\begin{array}{c}0.0138 \\
(0.0143)\end{array}$ & $\begin{array}{c}0.0275 \\
(0.0267)\end{array}$ \\
\hline Vocational training & $\begin{array}{c}0.0037 \\
(0.0090)\end{array}$ & $\begin{array}{c}0.0223 \\
(0.0151)\end{array}$ & $\begin{array}{c}0.0005 \\
(0.0111)\end{array}$ & $\begin{array}{c}0.0183 \\
(0.0234)\end{array}$ & $\begin{array}{c}0.0006 \\
(0.0112)\end{array}$ & $\begin{array}{c}0.0178 \\
(0.0233)\end{array}$ \\
\hline High school final diploma & Ref. & Ref. & Ref. & Ref. & Ref. & Ref. \\
\hline University diploma & $\begin{array}{l}-0.0028 \\
(0.0096)\end{array}$ & $\begin{array}{r}-0.0279 * \\
(0.0148)\end{array}$ & $\begin{array}{c}0.0147 \\
(0.0145)\end{array}$ & $\begin{array}{l}-0.0136 \\
(0.0251)\end{array}$ & $\begin{array}{c}0.0147 \\
(0.0145)\end{array}$ & $\begin{array}{l}-0.0146 \\
(0.0250)\end{array}$ \\
\hline \multicolumn{7}{|l|}{ Occupational status } \\
\hline Farmer or independent worker & $\begin{array}{c}-0.0323^{* * *} \\
(0.0069)\end{array}$ & $\begin{array}{c}-0.0478^{* * *} \\
(0.0139)\end{array}$ & $\begin{array}{c}-0.0197^{* *} \\
(0.0093)\end{array}$ & $\begin{array}{c}-0.0457^{* *} \\
(0.0222)\end{array}$ & $\begin{array}{c}-0.0201^{* *} \\
(0.0094)\end{array}$ & $\begin{array}{c}-0.0455^{* *} \\
(0.0222)\end{array}$ \\
\hline Executive & $\begin{array}{c}-0.0225 * * * \\
(0.0076)\end{array}$ & $\begin{array}{c}-0.0680 * * * \\
(0.0114)\end{array}$ & $\begin{array}{l}-0.0153 \\
(0.0094)\end{array}$ & $\begin{array}{c}-0.0700 * * * \\
(0.0199)\end{array}$ & $\begin{array}{l}-0.0158^{*} \\
(0.0095)\end{array}$ & $\begin{array}{c}-0.0699 * * * \\
(0.0199)\end{array}$ \\
\hline Intermediate professions & Ref. & Ref. & Ref. & Ref. & Ref. & Ref. \\
\hline Office worker & $\begin{array}{l}-0.0040 \\
(0.0092)\end{array}$ & $\begin{array}{c}0.0647 * * * \\
(0.0177)\end{array}$ & $\begin{array}{l}-0.0009 \\
(0.0124)\end{array}$ & $\begin{array}{c}0.1214^{* * *} \\
(0.0278)\end{array}$ & $\begin{array}{c}0.0001 \\
(0.0128)\end{array}$ & $\begin{array}{c}0.1228^{* * *} \\
(0.0278)\end{array}$ \\
\hline Blue-collar & $\begin{array}{l}0.0185^{*} \\
(0.0105)\end{array}$ & $\begin{array}{c}0.1042^{* * *} \\
(0.0145)\end{array}$ & $\begin{array}{c}0.0123 \\
(0.0114)\end{array}$ & $\begin{array}{c}0.1313^{* * *} \\
(0.0222)\end{array}$ & $\begin{array}{c}0.0136 \\
(0.0118)\end{array}$ & $\begin{array}{c}0.1324^{* * *} \\
(0.0222)\end{array}$ \\
\hline \multicolumn{7}{|l|}{$\begin{array}{l}\text { Characteristics of the spouse } \\
\text { Education }\end{array}$} \\
\hline No diploma & $\begin{array}{c}0.0314^{* *} \\
(0.0148)\end{array}$ & $\begin{array}{c}0.1354^{* * *} \\
(0.0199)\end{array}$ & $\begin{array}{c}0.0156 \\
(0.0156)\end{array}$ & $\begin{array}{c}0.1555^{* * *} \\
(0.0283)\end{array}$ & $\begin{array}{c}0.0171 \\
(0.0161)\end{array}$ & $\begin{array}{c}0.1545^{* * *} \\
(0.0283)\end{array}$ \\
\hline At most lower sec. edu. & $\begin{array}{l}0.0222^{*} \\
(0.0114)\end{array}$ & $\begin{array}{c}0.0756^{* * *} \\
(0.0160)\end{array}$ & $\begin{array}{c}0.0125 \\
(0.0136)\end{array}$ & $\begin{array}{c}0.0882^{* * *} \\
(0.0266)\end{array}$ & $\begin{array}{c}0.0134 \\
(0.0139)\end{array}$ & $\begin{array}{c}0.0868 * * * \\
(0.0266)\end{array}$ \\
\hline Vocational training & $\begin{array}{c}0.0123 \\
(0.0097)\end{array}$ & $\begin{array}{c}0.0765 * * * \\
(0.0145)\end{array}$ & $\begin{array}{c}0.0069 \\
(0.0114)\end{array}$ & $\begin{array}{c}0.0904^{* * * *} \\
(0.0238)\end{array}$ & $\begin{array}{c}0.0077 \\
(0.0117)\end{array}$ & $\begin{array}{c}0.0891^{* * *} \\
(0.0238)\end{array}$ \\
\hline High school final diploma & Ref. & Ref. & Ref. & Ref. & Ref. & Ref. \\
\hline University diploma & $\begin{array}{c}0.0115 \\
(0.0082)\end{array}$ & $\begin{array}{c}-0.0143 \\
(0.0129)\end{array}$ & $\begin{array}{c}0.0009 \\
(0.0109)\end{array}$ & $\begin{array}{l}-0.0240 \\
(0.0218)\end{array}$ & $\begin{array}{c}0.0008 \\
(0.0109)\end{array}$ & $\begin{array}{l}-0.0241 \\
(0.0218)\end{array}$ \\
\hline \multicolumn{7}{|l|}{ Nationality } \\
\hline French born in France & Ref. & Ref. & Ref. & Ref. & Ref. & Ref. \\
\hline Foreign nationality & $\begin{array}{l}0.0267^{*} \\
(0.0140)\end{array}$ & $\begin{array}{c}0.1191^{* * *} \\
(0.0231)\end{array}$ & $\begin{array}{c}0.0199 \\
(0.0159)\end{array}$ & $\begin{array}{c}0.1426 * * * \\
(0.0297)\end{array}$ & $\begin{array}{c}0.0215 \\
(0.0163)\end{array}$ & $\begin{array}{c}0.1406^{* * *} \\
(0.0295)\end{array}$ \\
\hline French born abroad & $\begin{array}{c}0.0218^{* *} \\
(0.0108)\end{array}$ & $\begin{array}{c}0.0674^{* * *} \\
(0.0181)\end{array}$ & $\begin{array}{c}0.0113 \\
(0.0107)\end{array}$ & $\begin{array}{c}0.0776 * * * \\
(0.0238)\end{array}$ & $\begin{array}{c}0.0120 \\
(0.0110)\end{array}$ & $\begin{array}{c}0.0772^{* * *} \\
(0.0237)\end{array}$ \\
\hline \multicolumn{7}{|l|}{ Instruments } \\
\hline Spouse works in eastern outskirts & & $\begin{array}{c}0.1123^{* * *} \\
(0.0212)\end{array}$ & & $\begin{array}{c}0.1327 * * * \\
(0.0279)\end{array}$ & & $\begin{array}{c}0.1335 * * * \\
(0.0281)\end{array}$ \\
\hline Girl-Boy & & & & & & $\begin{array}{l}-0.0231^{*} \\
(0.0136)\end{array}$ \\
\hline Correlation of residuals & 0.301 & $.1932)$ & 0.0853 & $0.1668)$ & 0.133 & $0.1802)$ \\
\hline LR test $\left(\rho_{12}=0\right)[\mathrm{p}$-value $]$ & 2.135 & $0.144]$ & 0.259 & $0.611]$ & 0.528 & $0.467]$ \\
\hline Log-likelihood & & & & & & \\
\hline Pseudo- $R^{2}$ & & & & & & 66 \\
\hline Number of observations & & & & & & 49 \\
\hline
\end{tabular}

Notes: ${ }^{* * *},{ }^{* *}$ and ${ }^{*}$ denote significance at the $1 \%, 5 \%$ and $10 \%$ level respectively.

Figures in parentheses give standard errors, corrected for within-neighborhood dependencies.

All models use $25 \%$ most deprived neighborhoods as neighborhood variable and are for all individuals in the sample (low and high educated together).

Table 4: Marginal effects from bivariate probit models with different instruments 


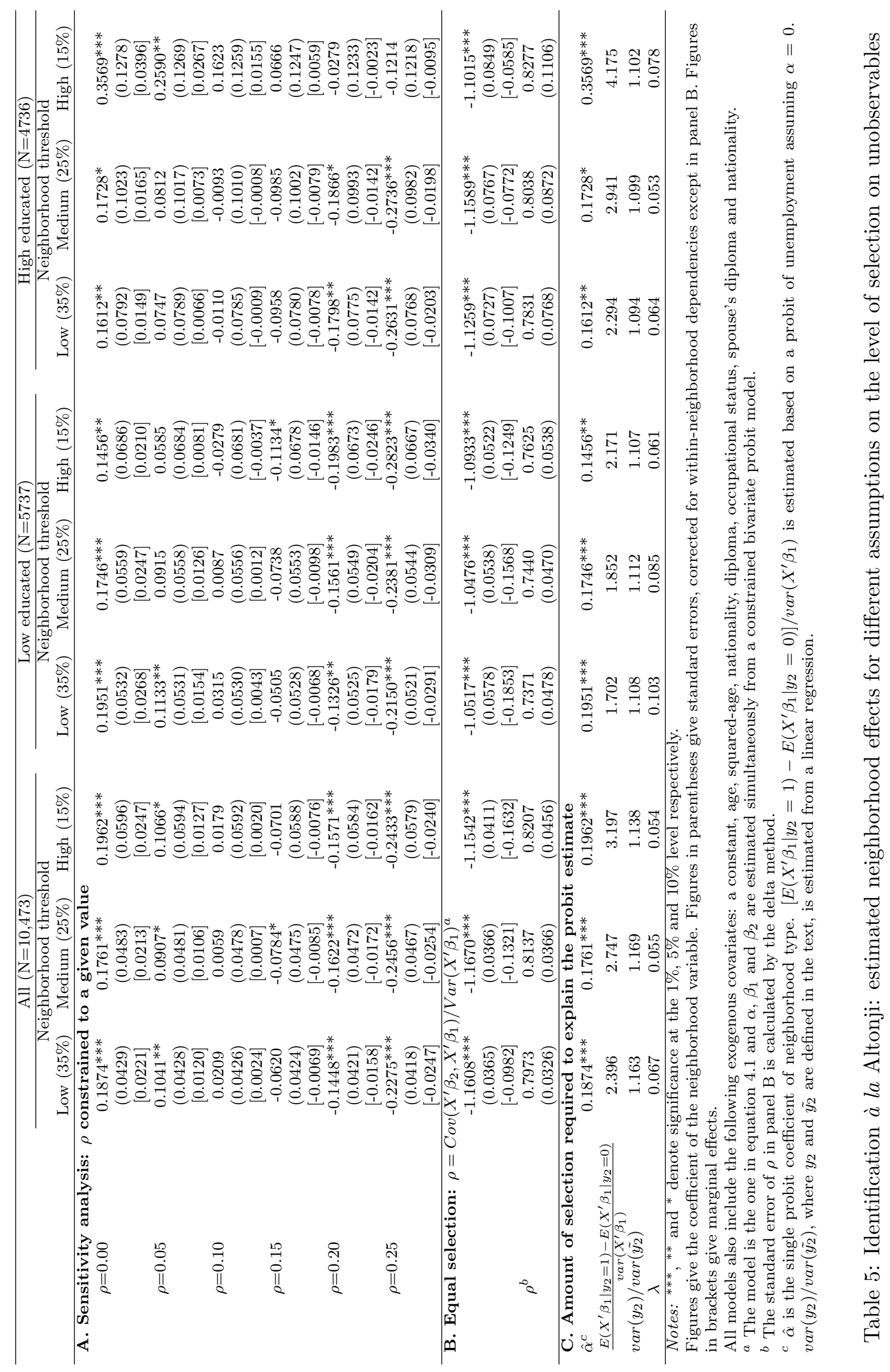




\section{Recent titles \\ CORE Discussion Papers}

2009/46. Daisuke OYAMA, Yasuhiro SATO, Takatoshi TABUCHI and Jacques-François THISSE. On the impact of trade on industrial structures: The role of entry cost heterogeneity.

2009/47. Ken-Ichi SHIMOMURA and Jacques-François THISSE. Competition among the big and the small.

2009/48. Frédéric BABONNEAU, Yurii NESTEROV and Jean-Philippe VIAL. Design and operations of gas transmission networks.

2009/49. Olivier BOS. How lotteries outperform auctions for charity.

2009/50. Nicolas BOCCARD and Xavier WAUTHY. Entry accommodation under multiple commitment strategies: judo economics revisited.

2009/51. Joachim GAHUNGU and Yves SMEERS. Multi-assets real options.

2009/52. Nicolas BOCCARD and Xavier WAUTHY. Regulating quality by regulating quantity: a case against minimum quality standards.

2009/53. David DE LA CROIX and Frédéric DOCQUIER. An incentive mechanism to break the lowskill immigration deadlock.

2009/54. Henry TULKENS and Vincent VAN STEENBERGHE. "Mitigation, adaptation, suffering": In search of the right mix in the face of climate change.

2009/55. Santanu S. DEY and Quentin LOUVEAUX. Split rank of triangle and quadrilateral inequalities.

2009/56. Claire DUJARDIN, Dominique PEETERS and Isabelle THOMAS. Neighbourhood effects and endogeneity issues.

2009/57. Marie-Louise LEROUX, Pierre PESTIEAU and Maria RACIONERO. Voting on pensions: sex and marriage.

2009/58. Jean J. GABSZEWICZ. A note on price competition in product differentiation models.

2009/59. Olivier BOS and Martin RANGER. All-pay auctions with endogenous rewards.

2009/60. Julio DAVILA and Marie-Louise LEROUX. On the fiscal treatment of life expectancy related choices.

2009/61. Luc BAUWENS and Jeroen V.K. ROMBOUTS. On marginal likelihood computation in change-point models.

2009/62. Jorge ALCALDE-UNZU and Elena MOLIS. Exchange of indivisible goods and indifferences: the Top Trading Absorbing Sets mechanisms.

2009/63. Pascal MOSSAY and Pierre M. PICARD. On spatial equilibria in a social interaction model.

2009/64. Laurence JACQUET and Dirk VAN DE GAER. A comparison of optimal tax policies when compensation or responsibility matter.

2009/65. David DE LA CROIX and Clara DELAVALLADE. Why corrupt governments may receive more foreign aid.

2009/66. Gilles GRANDJEAN, Ana MAULEON and Vincent VANNETELBOSCH. Strongly rational sets for normal-form games.

2009/67. Kristian BEHRENS, Susana PERALTA and Pierre M. PICARD. Transfer pricing rules, OECD guidelines, and market distortions.

2009/68. Marco MARINUCCI and Wouter VERGOTE. Endogenous network formation in patent contests and its role as a barrier to entry.

2009/69. Andréas HEINEN and Alfonso VALDESOGO. Asymmetric CAPM dependence for large dimensions: the Canonical Vine Autoregressive Model.

2009/70. Skerdilajda ZANAJ. Product differentiation and vertical integration in presence of double marginalization.

2009/71. Marie-Louise LEROUX and Grégory PONTHIERE. Wives, husbands and wheelchairs: Optimal tax policy under gender-specific health.

2009/72. Yu. NESTEROV and Levent TUNCEL. Local quadratic convergence of polynomial-time interior-point methods for conic optimization problems.

2009/73. Grégory VANDENBULCKE, Claire DUJARDIN, Isabelle THOMAS, Bas DE GEUS, Bart DEGRAEUWE, Romain MEEUSEN and Luc INT PANIS. Cycle commuting in Belgium: Spatial determinants and 're-cycling' strategies. 


\section{Recent titles}

\section{CORE Discussion Papers - continued}

2009/74. Noël BONNEUIL and Raouf BOUCEKKINE. Sustainability, optimality, and viability in the Ramsey model.

2009/75. Eric TOULEMONDE. The principle of mutual recognition - A source of divergence?

2009/76. David DE LA CROIX, Pierre PESTIEAU and Grégory PONTHIÈRE. How powerful is demography? The Serendipity Theorem revisited.

2009/77. Nicola ACOCELLA, Giovanni DI BARTOLOMEO, Andrew HUGUES HALLETT and Paolo G. PIACQUADIO. Announcement wars as an equilibrium selection device.

2009/78. Julio DÁVILA. The taxation of savings in overlapping generations economies with unbacked risky assets.

2009/79. Elena DEL REY and Miguel Angel LOPEZ-GARCIA. Optimal education and pensions in an endogenous growth model.

2009/80. Hiroshi UNO. Strategic complementarities and nested potential games.

2009/81. Xavier WAUTHY. Market coverage and the nature of product differentiation: a note.

2009/82. Filippo L. CALCIANO. Nash equilibria of games with increasing best replies.

2009/83. Jacques H. DRÈZE, Oussama LACHIRI and Enrico MINELLI. Stock prices, anticipations and investment in general equilibrium.

2009/84. Claire DUJARDIN and Florence GOFFETTE-NAGOT. Neighborhood effects on unemployment? A test à la Altonji.

\section{Books}

Public goods, environmental externalities and fiscal competition: 22 selected papers in public economics by Henry Tulkens, edited and introduced by Parkash Chander, Jacques Drèze, C. Knox Lovell and Jack Mintz, Springer, Boston 2006 (588 pp.).

V. GINSBURGH and D. THROSBY (eds.) (2006), Handbook of the economics of art and culture. Amsterdam, Elsevier.

J. GABSZEWICZ (ed.) (2006), La différenciation des produits. Paris, La découverte.

L. BAUWENS, W. POHLMEIER and D. VEREDAS (eds.) (2008), High frequency financial econometrics: recent developments. Heidelberg, Physica-Verlag.

P. VAN HENTENRYCKE and L. WOLSEY (eds.) (2007), Integration of AI and OR techniques in constraint programming for combinatorial optimization problems. Berlin, Springer.

P-P. COMBES, Th. MAYER and J-F. THISSE (eds.) (2008), Economic geography: the integration of regions and nations. Princeton, Princeton University Press.

J. HINDRIKS (ed.) (2008), Au-delà de Copernic: de la confusion au consensus ? Brussels, Academic and Scientific Publishers.

J-M. HURIOT and J-F. THISSE (eds) (2009), Economics of cities. Cambridge, Cambridge University Press.

\section{CORE Lecture Series}

C. GOURIÉROUX and A. MONFORT (1995), Simulation Based Econometric Methods.

A. RUBINSTEIN (1996), Lectures on Modeling Bounded Rationality.

J. RENEGAR (1999), A Mathematical View of Interior-Point Methods in Convex Optimization.

B.D. BERNHEIM and M.D. WHINSTON (1999), Anticompetitive Exclusion and Foreclosure Through Vertical Agreements.

D. BIENSTOCK (2001), Potential function methods for approximately solving linear programming problems: theory and practice.

R. AMIR (2002), Supermodularity and complementarity in economics.

R. WEISMANTEL (2006), Lectures on mixed nonlinear programming. 